\title{
Animal Spirits and Monetary Policy
}

\author{
PAUL DE GRAUWE
}

CESIFO WORKING PAPER NO. 2418

CATEGORY 6: MONETARY POLICY AND INTERnATIONAL FINANCE

OCTOBER 2008

\footnotetext{
An electronic version of the paper may be downloaded

- from the SSRN website: $\quad$ www.SSRN.com

- from the RePEc website: $\quad$ www.RePEc.org

- from the CESifo website: www.CESifo-group.org/wp
} 


\title{
Animal Spirits and Monetary Policy
}

\begin{abstract}
We develop a behavioral macroeconomic model in which agents use simple but biased rules to forecast future output and inflation. This model generates endogenous waves of optimism and pessimism ("Animal Spirits") that are generated by the correlation of biased beliefs. We contrast the dynamics of this model with a stylized DSGE-version of the model and we study the implications for monetary policies. One of our main results is that strict inflation targeting is suboptimal because it gives more scope for waves of optimism and pessimism to emerge thereby destabilizing output and inflation.
\end{abstract}

JEL Code: E10, E32, D83.

Keywords: DSGE-model, imperfect information, heuristics, animal spirits.

\author{
Paul De Grauwe \\ Faculty of Economics \\ University of Leuven \\ Naamsestraat 69 \\ 3000 Leuven \\ Belgium \\ paul.degrauwe@econ.kuleuven.be
}

September 2008

I am grateful to Stephan Fahr, Daniel Gros, Richard Harrison, Romain Houssa, Pablo Rovira Kaltwasser, Christian Keuschnigg, Giovanni Lombardo, Lars Ljungqvist, Ilbas Pelin, Frank Smets, Leopold von Thadden, and Tony Yates for their comments and suggestions on previous versions of this paper. 


\section{Introduction}

The idea that "animal spirits" drive the business cycle has been at the core of the macroeconomic dynamics described by Keynes. These "animal spirits" are defined as waves of optimism and pessimism gripping investors and consumers, and by having self-fulfilling properties, influencing output and investment. Although elusive as a concept, it has maintained a great popularity in discussions of the business cycle outside academia.

As a result of the systematic incorporation of rational expectations in macroeconomic models, the concept of "animal spirits" has been discarded from modern macroeconomic theory. If expectations are rational, there is simply no room for animal spirits to exert an independent influence on economic activity. In the currently fashionable DSGE-models that incorporate the rational expectations hypothesis together with a new Keynesian framework of wage and price rigidities, there is no place for such independent waves of optimism and pessimism. In these models all fluctuations in investment and output are the result of exogenous shocks in preferences, endowments and technologies that are slowly transmitted into the economy. This combination of exogenous shocks and slow transmission (inertia) creates cyclical movements in these models. In this sense the cyclical movements in output and prices in DSGE-models are created exogenously.

There have been serious attempts to incorporate the notion of "animal spirits" in dynamic general equilibrium models. This literature started with Azariadis(1981) and was further extended by Farmer and others (see Farmer and Guo(1994), Benhabib and Farmer(1994). These authors aim at developing rigorous models of the business cycle in which expectations are rational and aggregate fluctuations are driven by animal spirits. Typically these models produce multiple equilibria (sunspots). Together with random shocks they are capable of generating endogenous business cycles.

In this paper we present an alternative approach to modeling animal spirits. We do this because we believe that the notions of "animal spirits" and rational expectations do not mix well. The assumption of rational expectations implies that agents understand the underlying model structure and the distribution of the shocks. It also means that agents use the same information set, and can therefore be represented by one individual, the representative agent, who understands the "Truth". In such a 
framework it is difficult to understand how agents could be gripped by waves of optimism and pessimism.

The notion of animal spirits as developed by Keynes is based on the fact that individuals do not understand the "Truth". Individuals only understand small parts of the total information set, and they are not capable of describing the statistical distribution of economic shocks. The cognitive limitations of individuals have now been abundantly documented by psychologists and brain scientists (For recent surveys, see Kahneman and Thaler (2006) and Della Vigna(2007). See also Thaler(1994), Camerer and Lovallo, (1999), Read and van Leeuwen, 1998). As a result of these cognitive limitations, there is also heterogeneity in the use of information.

The world of imperfect information and cognitive limitation of individuals is the world in which Keynes set up his idea of "animal spirits". This is also the context in which this paper introduces them. We will take the view that agents face cognitive problems in understanding and processing information. As a result, they use simple rules ("heuristics") to guide their behaviour (see Gabaix, Laibson, Moloche, and Weinberg, 2006). They do this not because they are irrational, but rather because the complexity of the world is overwhelming. In a way it can be said that using heuristics is a rational response of agents who are aware of their limited capacity to understand the world. The challenge when we try to model heuristics will be to introduce discipline in the selection of rules so as to avoid that "everything becomes possible".

In this paper we develop a parsimonious model capable of generating endogenous and self-fulfilling waves of optimism and pessimism in an otherwise standard setup. We look for parsimony because we wish to find out what is the simplest possible model needed to generate such cycles. As will become clear extremely simple rules are capable of generating a very complex dynamics.

\section{A behavioral macroeconomic model}

In this section we describe our modeling strategy. We do this by presenting a standard aggregate-demand-aggregate supply model augmented with a Taylor rule. The novel feature of the model is that agents use simple rules, heuristics, to forecast the future. These rules are subjected to a selection mechanism. Put differently, agents will 
endogenously select the forecasting rules that have delivered the highest fitness in the past. This selection mechanism acts as a disciplining device on the kind of rules that are acceptable. Since agents use different heuristics we also obtain heterogeneity. This, as will be shown, creates endogenous business cycles.

We will contrast this model with a similar model that incorporates rational expectations, and that we interpret as a stylized version of DSGE-models. This comparison will also allow us to focus on some crucial differences in the transmission of shocks, in particular of monetary policy shocks.

Obviously, the approach presented here is not the only possible one. In fact, a large literature has emerged attempting to introduce imperfect information into macroeconomic models. These attempts have been based mainly on the statistical learning approach pioneered by Sargent(1993) and Evans and Honkapohja(2001). This literature leads to important new insights (see e.g. Gaspar and Smets(2006), Orphanides and Williams(2004), Milani(2007a)). However, we feel that this approach still loads individual agents with too many cognitive skills that they probably do not posses in the real world ${ }^{1}$. A similar criticism can be developed against another approach at modeling imperfect information based on "rational inattention" (see Mackowiak and Wiederholt(2005), Sims(2005)).

Our approach is also not the first attempt to introduce heuristics into macroeconomic models. Recently, Brazier et al. (2006) have done so in the context of an overlapping generations model, and Branch and Evans(2006) have developed models with imperfectly informed agents. In addition, there is a large literature of behavioural finance models that now incorporate the view that agents are limited in their cognitive skills and use heuristics to guide their behaviour and forecasting (see Brock and Hommes(1997), Lux and Marchesi(2000), De Grauwe and Grimaldi(2006)).

\subsection{The model}

The model consists of an aggregate demand equation, an aggregate supply equation and a Taylor rule.

\footnotetext{
${ }^{1}$ See the fascinating book of Gigerenzer and Todd(1999) on the use of simple heuristics as compared to statistical (regression) learning.
} 
The aggregate demand equation can be derived from dynamic utility maximization. This produces an Euler equation in the same vain as in DSGE-models. We obtain

$$
y_{t}=a_{1} \widetilde{E}_{t} y_{t+1}+\left(1-a_{1}\right) y_{t-1}+a_{2}\left(r_{t}-\widetilde{E}_{t} \pi_{t+1}\right)+\varepsilon_{t}
$$

where $y_{t}$ is the output gap in period $\mathrm{t}, r_{t}$ is the nominal interest rate, $\pi_{t}$ is the rate of inflation, and $\varepsilon_{t}$ is a white noise disturbance term. $\widetilde{E}_{t}$ is the expectations operator where the tilde above $E$ refers to expectations that are not formed rationally. We will specify this process subsequently. We follow the procedure introduced in DSGEmodels of adding a lagged output in the demand equation. This is usually justified by invoking habit formation. We keep this assumption here as we want to compare the heuristic model with the DSGE-rational expectations model. However, we will show in section 5 that we do not really need this inertia-building device to generate inertia in the endogenous variables.

The aggregate supply equation can be derived from profit maximization of individual producers. We assume as in DSGE-models a Calvo pricing rule and the use of some indexation rule used in adjusting prices, which leads to a lagged inflation variable in the equation ${ }^{2}$. The supply curve can also be interpreted as a New Keynesian Philips curve. We obtain:

$$
\pi_{t}=b_{1} \widetilde{E}_{t} \pi_{t+1}+\left(1-b_{1}\right) \pi_{t-1}+b_{2} y_{t}+\eta_{t}
$$

Finally the Taylor rule describes the behaviour of the central bank

$$
r_{t}=c_{1}\left(\pi_{t}-\pi_{t}^{*}\right)+c_{2} y_{t}+c_{3} r_{t-1}+u_{t}
$$

where $\pi_{t}^{*}$ is the inflation target which for the sake of convenience will be set equal to 0 . Note that we assume, as is commonly done, that the central bank smoothens the interest rate. This smoothing behaviour is represented by the lagged interest rate in equation (3). Ideally, the Taylor rule should be formulated using a forward looking inflation variable, i.e. central banks set the interest rate on the basis of their forecasts

\footnotetext{
${ }^{2}$ It is now standard in DSGE-models to use a pricing equation in which marginal costs enter on the right hand side. Such an equation is derived from profit maximisation in a world of imperfect competition. It can be shown that under certain conditions the aggregate supply equation (3) is equivalent to such a pricing equation (see Gali(2008), Smets and Wouters(2003)).
} 
about the rate of inflation. We have not done so here in order to maintain simplicity in the model.

We assume that agents use simple rules (heuristics) to forecast the future output and inflation. The way we proceed is as follows. We start with a very simple heuristics for forecasting and apply it to the forecasting rules of future output. We assume that because agents do not fully understand how the output gap is determined, their forecasts are biased. We assume that some agents are optimistic and systematically bias the output gap upwards, others are pessimistic and systematically bias the output gap downwards.

The optimists are defined by $\widetilde{E}_{t}^{o p t} y_{t+1}=g_{t}$

The pessimists are defined by $\widetilde{E}_{t}^{p e s} y_{t+1}=-g_{t}$

where $g_{t}>0$ expresses the degree of bias in estimating the output gap. The expression $d_{t}=2 g_{t}$ can be interpreted as the divergence in beliefs among agents about the output gap. We will assume that this divergence in beliefs is itself a function of the variance in the output gap. Thus we write

$$
d_{t}=\beta+\delta \operatorname{var}\left(y_{t}\right)
$$

where $\beta \geq 0$ and $\delta \geq 0$. The logic is that when the uncertainty about the output gap increases the agents' beliefs about the true output gap tend to diverge more. We will, however, also analyze the special case where $\delta=0$, i.e. the divergence in beliefs is constant and equal to $\beta$. In that case $g_{t}$ in (4) and (5) is constant and equal to $\frac{\beta}{2}$.

Note that we do not consider this assumption of a simple bias to be a realistic representation of the how agents forecast. Rather is it a parsimonious representation of a world where agents do not know the "truth" (i.e. the underlying model) and have a biased view about this truth. It will be shown that such a simple assumption is capable of generating very complex waves of optimism and pessimisms. Our aim is also to contrast the dynamics obtained in a model using such a simple heuristics with the one obtained in models where agents are assumed to know the "truth".

The market forecast is obtained as a weighted average of these two forecasts, i.e. 


$$
\begin{aligned}
& \widetilde{E}_{t} y_{t+1}=\alpha_{o p t, t} \widetilde{E}_{t}^{o p t} y_{t+1}+\alpha_{p e s, t} \widetilde{E}_{t}^{p e s} \\
& \widetilde{E}_{t} y_{t+1}=\alpha_{o p t, t} g-\alpha_{p e s, t} g \\
& \text { and } \alpha_{o p t, t}+\alpha_{p e s, t}=1
\end{aligned}
$$

where $\alpha_{o p t, t}$ and $\alpha_{\text {pes,t }}$ are the weights of optimists, receptively, pessimists in the market. As will be shown later, this market forecast will turn out to be unbiased on average.

A methodological issue arises here. The forecasting rules (heuristics) introduced here are not derived at the micro level and then aggregated. Instead, they are imposed ex post, once the demand and supply equations are derived. This has also been the approach in the learning literature pioneered by Evans and Honkapohja(2001). Ideally one would like to derive the heuristics from the micro-level in an environment in which agents experience cognitive problems. Our knowledge about how to model this behaviour at the micro level ${ }^{3}$ and how to aggregate it is too sketchy, however, and we have not tried to do so.

As indicated earlier, agents are rational in the sense that they continuously evaluate their forecast performance. We follow Brock and Hommes(1997) in specifying the procedure agents follow in this evaluation process. Recently, Branch and Evans(2006) also introduced this selection mechanism in a macroeconomic model.

Agents compute the forecast performance of the different heuristics as follows:

$$
\begin{aligned}
& U_{o p t, t}=-\sum_{k=1}^{\infty} \omega_{k}\left[y_{t-k}-\widetilde{E}_{o p t, t-k-1} y_{t-k}\right]^{2} \\
& U_{p e s, t}=-\sum_{k=1}^{\infty} \omega_{k}\left[y_{t-k}-\widetilde{E}_{p e s, t-k-1} y_{t-k}\right]^{2}
\end{aligned}
$$

where $U_{o p t, t}$ and $U_{\text {pes,t }}$ are the forecast performances of the optimists and pessimists, respectively. These are defined as the mean squared forecasting errors (MSFEs) of the optimistic and pessimistic forecasting rules; $\omega_{k}$ are geometrically declining weights.

\footnotetext{
${ }^{3}$ Psychologists and brains scientists struggle to understand how our brain processes information. There is as yet no generally accepted model we could use to model the micro-foundations of information processing.
} 
The proportion of agents using the optimistic and the pessimistic forecasting rules is then determined in the following way (Brock-Hommes $(1997))^{4}$ :

$$
\begin{aligned}
& \alpha_{o p t, t}=\frac{\exp \left(\gamma U_{o p t, t}\right)}{\exp \left(\gamma U_{o p t, t}\right)+\exp \left(\gamma U_{p e s, t}\right)} \\
& \alpha_{p e s, t}=\frac{\exp \left(\gamma U_{p e s, t}\right)}{\exp \left(\gamma U_{o p t, t}\right)+\exp \left(\gamma U_{p e s, t}\right)}=1-\alpha_{o p t, t}
\end{aligned}
$$

Equation (12) says that as the past forecast performance of the optimists improves relative to that of the pessimists more agents will select the optimistic belief about the output gap for their future forecasts. As a result the proportion of agents using the optimistic rule increases. Equation (13) has a similar interpretation. The parameter $\gamma$ measures the "intensity of choice", i.e. the intensity with which agents allow their choice for a particular heuristic to depend on past forecast performance. In the limit when $\gamma=\infty$ only one, the best performing heuristic, will be selected.

Note that this selection mechanism is the disciplining device introduced in this model on the kind of rules of behaviour that are acceptable. Only those rules that pass the fitness test remain in place. The others are weeded out. In contrast with the disciplining device implicit in rational expectations models which implies that agents have superior cognitive capacities, we do not have to make such an assumption here.

It is also useful to point out that the selection mechanism used here can be interpreted as an evolutionary one that allows high forecasting performance to spread throughout the economy through replication.

Agents also make forecasts of inflation in this model. At this stage of the analysis we will simply assume that all agents perceive the central bank's announced inflation target $\pi_{t}^{*}$ to be fully credible. They use this value as their forecast of future inflation, i.e. $\widetilde{E}_{t} \pi_{t+1}=\pi_{t}^{*}$ (where for the sake of simplicity we assume the inflation target to be equal to 0$)$. We will extend this simple inflation forecasting process in a later section when we will also assume that there is heterogeneity of beliefs in the inflation forecasting process. We keep homogeneity of beliefs here to focus on the impact of heterogeneity in the forecasting of future output gaps.

\footnotetext{
${ }^{4}$ Such a specification is often used in discrete choice theory. See Anderson, de Palma, and Thisse, (1992)
} 
The solution of the model is found by first substituting (3) into (1) and rewriting in matrix notation. This yields:

$\left[\begin{array}{cc}1 & -b_{2} \\ -a_{2} c_{1} & 1-a_{2} c_{2}\end{array}\right]\left[\begin{array}{l}\pi_{t} \\ y_{t}\end{array}\right]=\left[\begin{array}{cc}b_{1} & 0 \\ -a_{2} & a_{1}\end{array}\right]\left[\begin{array}{c}\widetilde{E}_{t} \pi_{t+1} \\ \widetilde{E}_{t} y_{t+1}\end{array}\right]+\left[\begin{array}{cc}1-b_{1} & 0 \\ 0 & 1-a_{1}\end{array}\right]\left[\begin{array}{c}\pi_{t-1} \\ y_{t-1}\end{array}\right]+\left[\begin{array}{c}0 \\ a_{2} c_{3}\end{array}\right] r_{t-1}+\left[\begin{array}{c}\eta_{t} \\ a_{2} u_{t}+\varepsilon_{t}\end{array}\right]$

or

$$
A Z_{t}=B \tilde{E}_{t} Z_{t}+C Z_{t-1}+b r_{t-1}+v_{t}
$$

where bold characters refer to matrices and vectors. The solution for $Z_{t}$ is given by

$$
Z_{t}=A^{-1}\left|B \tilde{E}_{t} Z_{t}+C Z_{t-1}+b r_{t-1}+v_{t}\right|
$$

The solution exists if the matrix $\boldsymbol{A}$ is non-singular, i.e. if $\left(1-a_{2} c_{2}\right) a_{2} b_{2} c_{1} \neq 0$. The system (15) describes the solution for $y_{t}$ and $\pi_{t}$ given the forecasts of $y_{t}$ and $\pi_{t}$. The latter have been specified in equations (4) to (13) and can be substituted into (15). Finally, the solution for $r_{t}$ is found by substituting $y_{t}$ and $\pi_{t}$ obtained from (15) into (3).

Our research strategy consists in comparing the dynamics of this heuristic model with the same structural model (aggregate demand equation (1), aggregate supply equation (2) and Taylor rule equation (3)) under rational expectations which we interpret as a stylized DSGE-model. .

The model consisting of equations (1) to (3) can be written in matrix notation as follows:

$$
\begin{gathered}
{\left[\begin{array}{ccc}
1 & -b_{2} & 0 \\
0 & 1 & -a_{2} \\
-c_{1} & -c_{2} & 1
\end{array}\right]\left[\begin{array}{l}
\pi_{t} \\
y_{t} \\
r_{t}
\end{array}\right]=\left[\begin{array}{ccc}
b_{1} & 0 & 0 \\
-a_{2} & a_{1} & 0 \\
0 & 0 & 0
\end{array}\right]\left[\begin{array}{c}
E_{t} \pi_{t+1} \\
E_{t} y_{t+1} \\
E_{t} r_{t+1}
\end{array}\right]+\left[\begin{array}{ccc}
1-b_{1} & 0 & 0 \\
0 & 1-a_{1} & 0 \\
0 & 0 & a_{3}
\end{array}\right]\left[\begin{array}{c}
\pi_{t-1} \\
y_{t-1} \\
r_{t-1}
\end{array}\right]+\left[\begin{array}{c}
\eta_{t} \\
\varepsilon_{t} \\
u_{t}
\end{array}\right]} \\
\Omega \mathrm{Z}_{\mathrm{t}}=\Phi \mathrm{E}_{\mathrm{t}} \mathrm{Z}_{\mathrm{t}}+\Lambda \mathrm{Z}_{\mathrm{t}-1}+\mathrm{v}_{\mathrm{t}} \\
\mathrm{Z}_{\mathrm{t}}=\Omega^{-1}\left[\Phi \mathrm{E}_{\mathrm{t}} \mathrm{Z}_{\mathrm{t}}+\Lambda \mathrm{Z}_{\mathrm{t}-1}+\mathrm{v}_{\mathrm{t}}\right]
\end{gathered}
$$


This model can be solved under rational expectations using the Binder-Pesaran(1996) procedure.

\subsection{Calibrating the behavioral and the rational model}

We proceed by calibrating the model. In appendix A we present the parameters used in the calibration exercise. We have calibrated the model in such a way that the time units can be considered to be months. In section 5 we present a sensitivity analysis of the main results to changes in the main parameters of the model.

We show the results of a simulation exercise in which the three shocks (demand shocks, supply shocks and interest rate shocks) are i.i.d. with standard deviations of $0.5 \%$.

We first present a simulation in the time domain. Figure 1 shows the time pattern of output and inflation produced by the behavioral model. We observe a strong cyclical movement in the output gap. The source of these cyclical movements is seen to be the weight of optimists and pessimists in the market (see second panel of figure 1). The model in fact generates endogenous waves of optimism and pessimism. During some periods pessimists dominate and this translates into below average output growth. These pessimistic periods are followed by optimistic ones when optimistic forecasts tend to dominate and the growth rate of output is above average. These waves of optimism and pessimism are essentially unpredictable. Other realizations of the shocks produce different cycles with the same general characteristics.

These endogenously generated cycles in output are made possible by a self-fulfilling mechanism that can be described as follows. A series of random shocks creates the possibility that one of the two forecasting rules, say the optimistic one, delivers a higher payoff, i.e. a lower mean squared forecast error (MSFE). This attracts agents that were using the pessimistic rule. The "contagion-effect" leads to an increasing use of the optimistic belief to forecast the output-gap, which in turn stimulates aggregate demand. Optimism is therefore self-fulfilling. A boom is created. At some point, negative stochastic shocks make a dent in the MSFE of the optimistic forecasts. The pessimistic belief becomes attractive and therefore fashionable again. The economy turns around. 
These waves of optimism and pessimism can be understood to be searching mechanisms of agents who do not fully understand the underlying model but are continuously searching for the truth. An essential characteristics of this searching mechanism is that it leads to systematic correlation in beliefs (either optimistic or pessimistic ones). This systematic correlation is at the core of the booms and busts created in the model. Note, however, that when computed over a significantly large period of time the average error in the forecasting goes to zero. In this sense, the forecast bias tends to disappear asymptotically.

\section{Figure 1: Output gap and inflation in behavioral model}
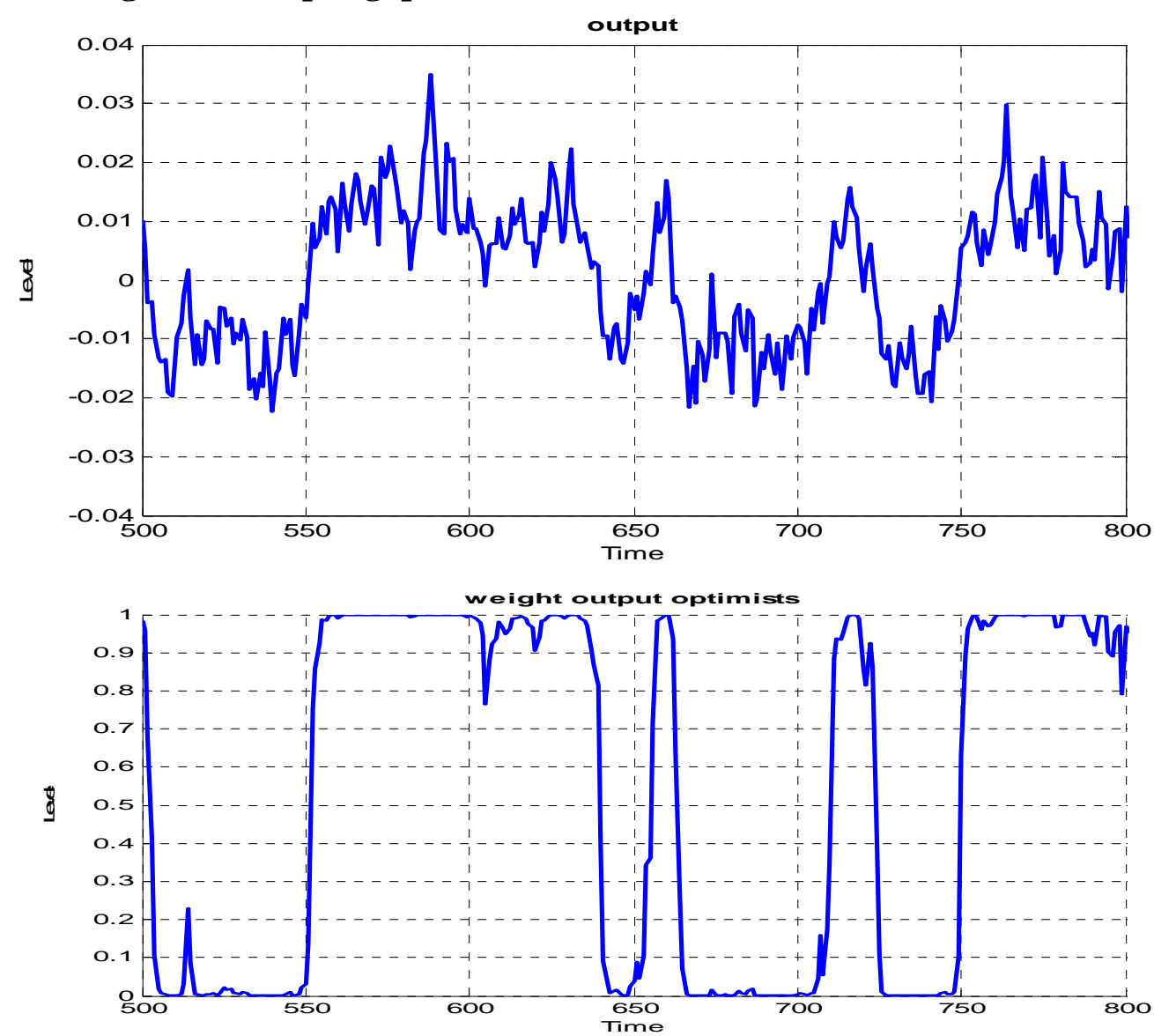


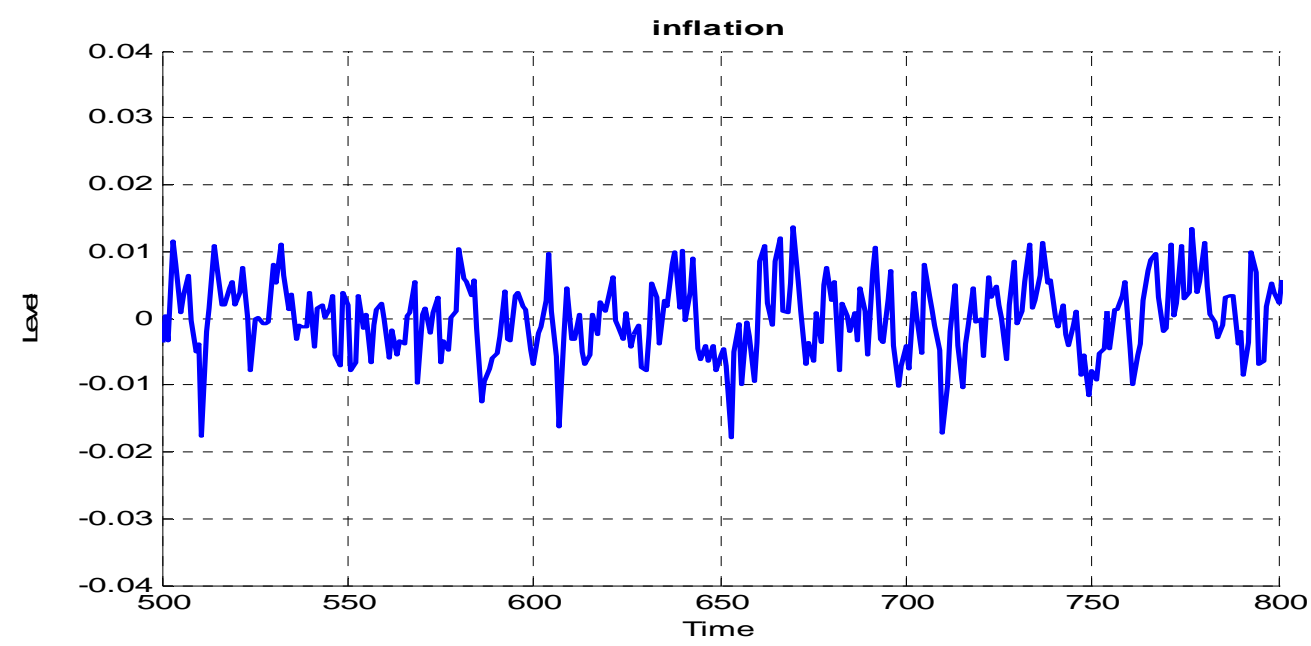

From figure 1 (third panel) we observe that inflation is relatively stable and fluctuates around the target (set at 0 ) in a relatively narrow band. This result has everything to do with our assumption that agents are homogeneous in giving full credibility to the inflation target of the central bank. We will return to this when we introduce heterogeneity among agents in their perception of the credibility of the central bank's inflation target.

We contrast these results with those obtained using the model under rational expectations. We use the same structural model with the same parameter values for the aggregate demand, supply and Taylor equations. In addition the shocks are the same with the same iid structure.

We show the results in figure 2. Two differences stand out. First the rational expectations model does not produce clear cyclical movements in the output gap. In a way this is not surprising: the shocks are white noise and the transmission mechanism exhibits a minimal degree of inertia. In full-fledged DSGE-models the inertia is more complex and the shocks typically exhibit autoregressive patterns that are important in producing cyclical movements in output. Thus our results confirm that the cycles produced in the DSGE models come to a large extent from outside the model. We return to this issue in section 6 where we analyze the degree of inertia produced by the two models.

Second, the volatility of output and inflation is higher in the rational expectations model compared to the behavioral model. This can also be seen from table 1 where we show the standard deviations of the output gap and inflation in the two models. Again this has to do with the minimal inertia assumed in the underlying structural 
model. Much of the attempt to fit the rational expectations model (DSGE-models) has consisted in adding additional lags so as to produce more persistence and less shortterm volatility.

\section{Figure 2: Output gap and inflation in the rational model}
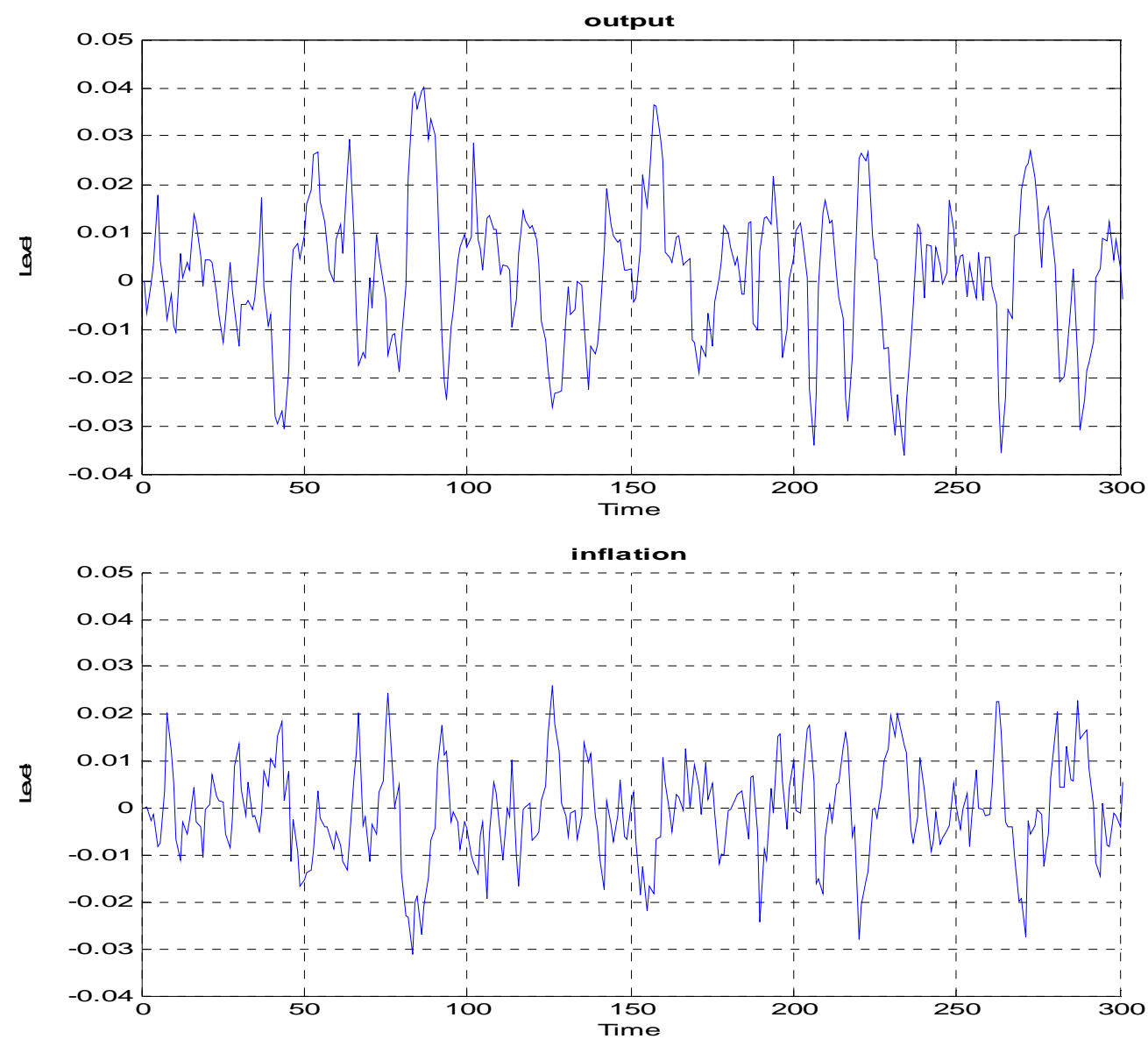

Table $1:$ Standard deviations of output gap and inflation

behavioral model rational model

output gap $\quad 0.86 \quad 1.35$

$\begin{array}{lll}\text { inflation } & 0.56 & 0.89\end{array}$

Note: these standard deviations are the averages obtained from simulating the model 1000 times, each time over 1000 periods

\subsection{Impulse responses in the behavioral and the rational model}

The next step in the analysis is to compute the impulse responses to shocks. Here we focus on the impulse responses to an interest rate shock, defined as plus one standard deviation of the shock in the Taylor equation. 
The peculiarity of the behavioral model is that for the same parameters of the model the impulse responses are different for each realization of the stochastic shocks. This contrasts with the rational expectations model where the impulse response functions are not sensitive to the realization of the stochastic shocks (keeping the parameters unchanged). We will return to this difference and give it an interpretation.

Figure 3 shows the mean impulse responses to an interest rate shock. We constructed the mean response by simulating the model 100 times with 100 different realizations of the shocks. We then computed the mean response together with the standard deviations. Figure 3 shows the mean response (the dotted lines are the mean response + and -2 standard deviations; note also that we introduced the shock after 100 periods). We obtain the standard result of an interest rate shock on output and inflation. However, the uncertainty surrounding this result is considerable at least in the short run.

Where does this uncertainty come from? Not from parameter uncertainty. We use the same parameters in constructing all our impulse responses. The answer is that in this behavioral model each realization of the shocks creates different waves of optimism and pessimism (animal spirits). We could also call these "market sentiments". Thus a shock that occurs in period 100 in one simulation happens in a different market sentiment than the same shock in another simulation. In addition, the shock itself affects market sentiments. As a result, the short-term effects of the same interest rate shock become very hard to predict. In section 2.6 we elaborate further on this theme and illustrate how particular differences in "market sentiments" affect the impulse responses to shocks.

Another way to interpret this result is to say that the timing of the shock is important. The same shocks applied at different times can have very different short-term effects on inflation and output. In other words, history matters. Note that the uncertainty about the impulse responses tends to disappear in the long run, as the effect of shortterm differences in market sentiments disappears. 
Figure 3: Mean impulse responses to interest rate shock in the behavioral model
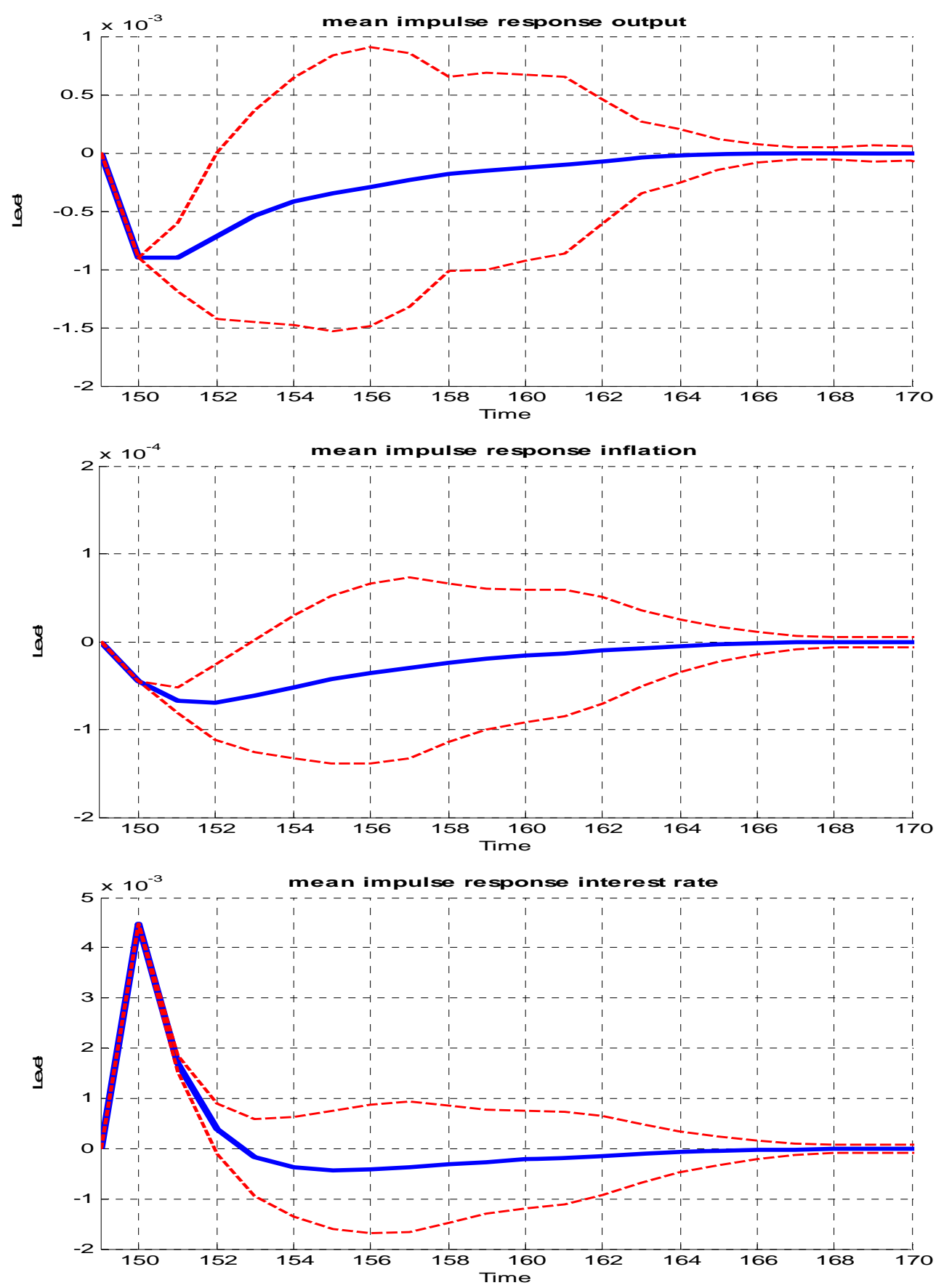

Note: The dotted lines represent the impulse responses with $+/-2$ standard deviations

This difference in the nature of uncertainty in a behavioral and a rational expectations model has everything to do with the fact that the former has non-linear features while the latter is linear. Thus the additional uncertainty produced by the behavioral model, i.e. the dependence of the impulse response functions on the state of the economy is the outcome of its non-linearity. Rational expectations models including the DSGE- 
models traditionally impose some linearization procedure. This is done for the sake of mathematical simplicity. It leads to a problem though. If the microfoundation of the model leads to a non-linear model, it is important to know how this non-linearity (which is part of the micro-foundation) affects the dynamics generated by the model. Eliminating these non-linearities amounts to destroying information that is relevant to predict the transmission of shocks. This may not matter much for the long run, but since the DSGE-models have the ambition of forecasting the transmission process, it is of significant importance.

\subsection{The extended behavioral model}

In this section we extend the behavioral model by allowing the inflation forecasters to be heterogeneous. We follow Brazier et al. (2006) in allowing for two inflation forecasting rules. One rule is based on the announced inflation target (as in the previous section); the other rule extrapolates inflation from the past into the future. One may argue that this is quite a different pair of heuristics than in the case of output forecasting. The difference between inflation forecasting and output forecasting is that in the former case there is a central bank that announces a particular inflation target. This target works as an anchor for the forecasts of agents. Such an anchor is absent in the case of output forecasting.

The "inflation targeters" use the central bank's inflation target to forecast future inflation, i.e.

$$
\widetilde{E}_{t}^{t a r}=\pi_{t}^{*}
$$

where as before we set the inflation target $\pi_{t}^{*}=0$

The "extrapolators" are defined by $E_{t}^{e x t}=\pi_{t-1}$

The market forecast is a weighted average of these two forecasts, i.e.

$$
\widetilde{E}_{t} \pi_{t+1}=\beta_{\text {tar }, t} \widetilde{E}_{t}^{t a r} \pi_{t+1}+\beta_{\text {ext }, t} \widetilde{E}_{t}^{\text {ext }} \pi_{t+1}
$$

or

$$
\begin{aligned}
& E_{t} \pi_{t+1}=\beta_{t a r, t} \pi_{t}^{*}+\beta_{e x t, t} \pi_{t-1} \\
& \text { and } \beta_{t a r, t}+\beta_{\text {ext }, t}=1
\end{aligned}
$$


We use the same selection mechanism as in the previous section based on the mean squared forecasting errors produced by the two rules to determine the proportions of agents trusting the inflation target and those who do not trust it and revert to extrapolation of past inflation, i.e.

$$
\begin{aligned}
& \beta_{\text {tar }, t}=\frac{\exp \left(\gamma U_{t a r, t}\right)}{\exp \left(\gamma U_{t a r, t}\right)+\exp \left(\gamma U_{\text {ext }, t}\right)} \\
& \beta_{\text {ext }, t}=\frac{\exp \left(\gamma U_{\text {ext }, t}\right)}{\exp \left(\gamma U_{t a r, t}\right)+\exp \left(\gamma U_{\text {ext }, t}\right)}
\end{aligned}
$$

This inflation forecasting heuristics can be interpreted as a procedure of agents to find out how credible the central bank's inflation targeting is. If this is very credible, using the announced inflation target will produce good forecasts and as a result, the proportion of agents relying on the inflation target will be high. If on the other hand the inflation target does not produce good forecasts (compared to a simple extrapolation rule) it will not be used much and therefore the proportion of agents using it will be small.

We calibrated the model using the same parameters as in the previous section. We first show the results in the time domain and then discuss the impulse response functions.

Figure 4 presents the results for the output gap in the time domain. We find the same cycles in the output gap as in the previous section. Again these cycles are related to the waves of optimism and pessimism in the forecasting (second panel in figure 4).

The results concerning the time path of inflation are shown in figure 5. We first concentrate on the second panel of figure 5. This shows the proportion of "extrapolators", i.e. the agents who do not trust the inflation target of the central bank. We can identify two regimes. There is a regime in which the proportion of extrapolators fluctuates around 50\% which also implies that the proportion of forecasters using the inflation target as their guide (the "inflation targeters") is around $50 \%$. This is sufficient to maintain the rate of inflation within a narrow band of approximately + and $-1 \%$ around the central bank's inflation target. There is a second regime though which occurs when the extrapolators are dominant. During this regime the rate of inflation fluctuates significantly more. Thus the inflation targeting 
of the central bank is fragile. It can be undermined when forecasters decide that relying on past inflation movements produces better forecast performances than relying on the central bank's inflation target. This can occur quite unpredictably as a result of stochastic shocks in supply and/or demand.

Figure 4: Output gap in the extended behavioral model
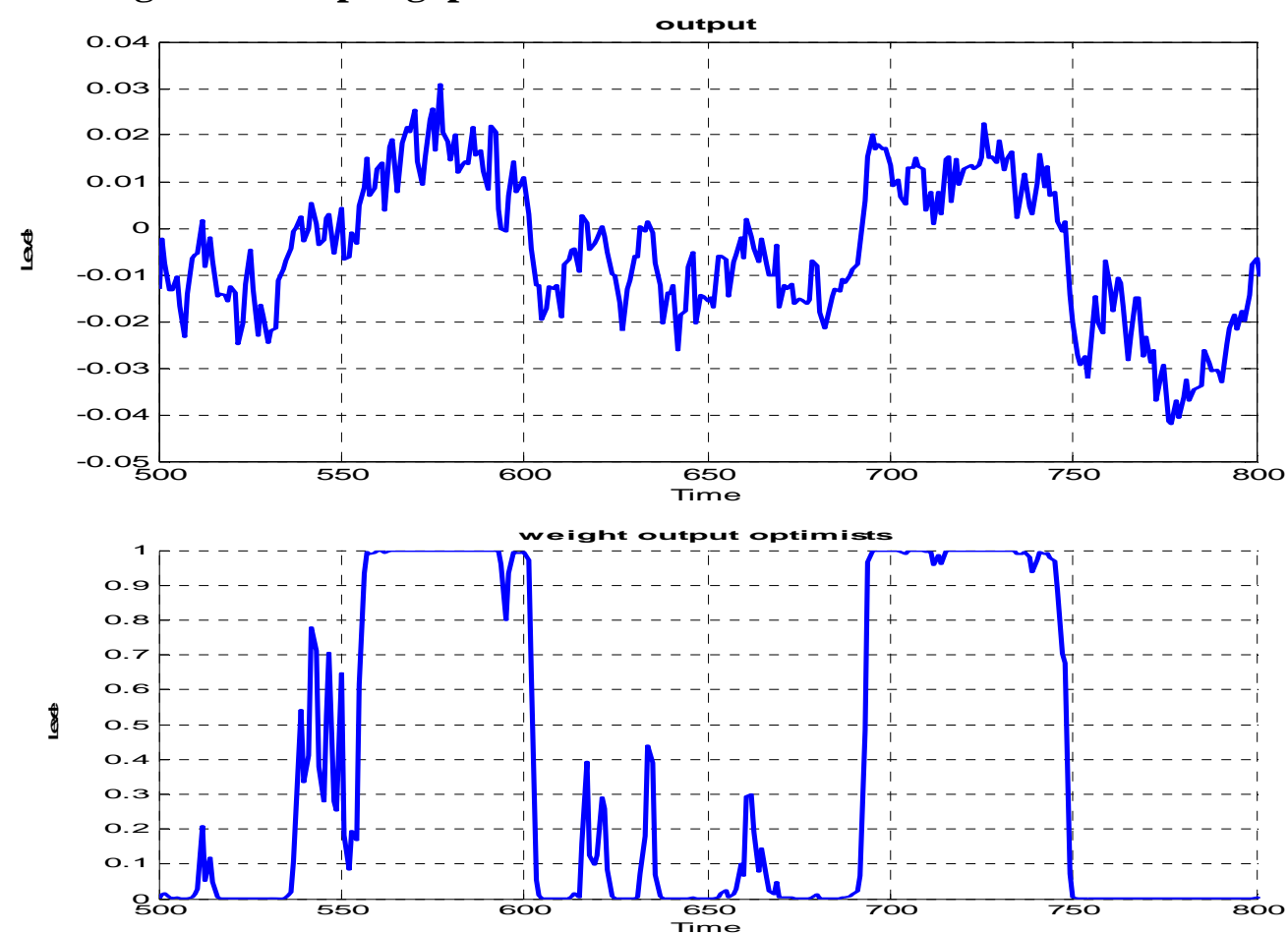

Figure 5: Inflation in the extended behavioral model
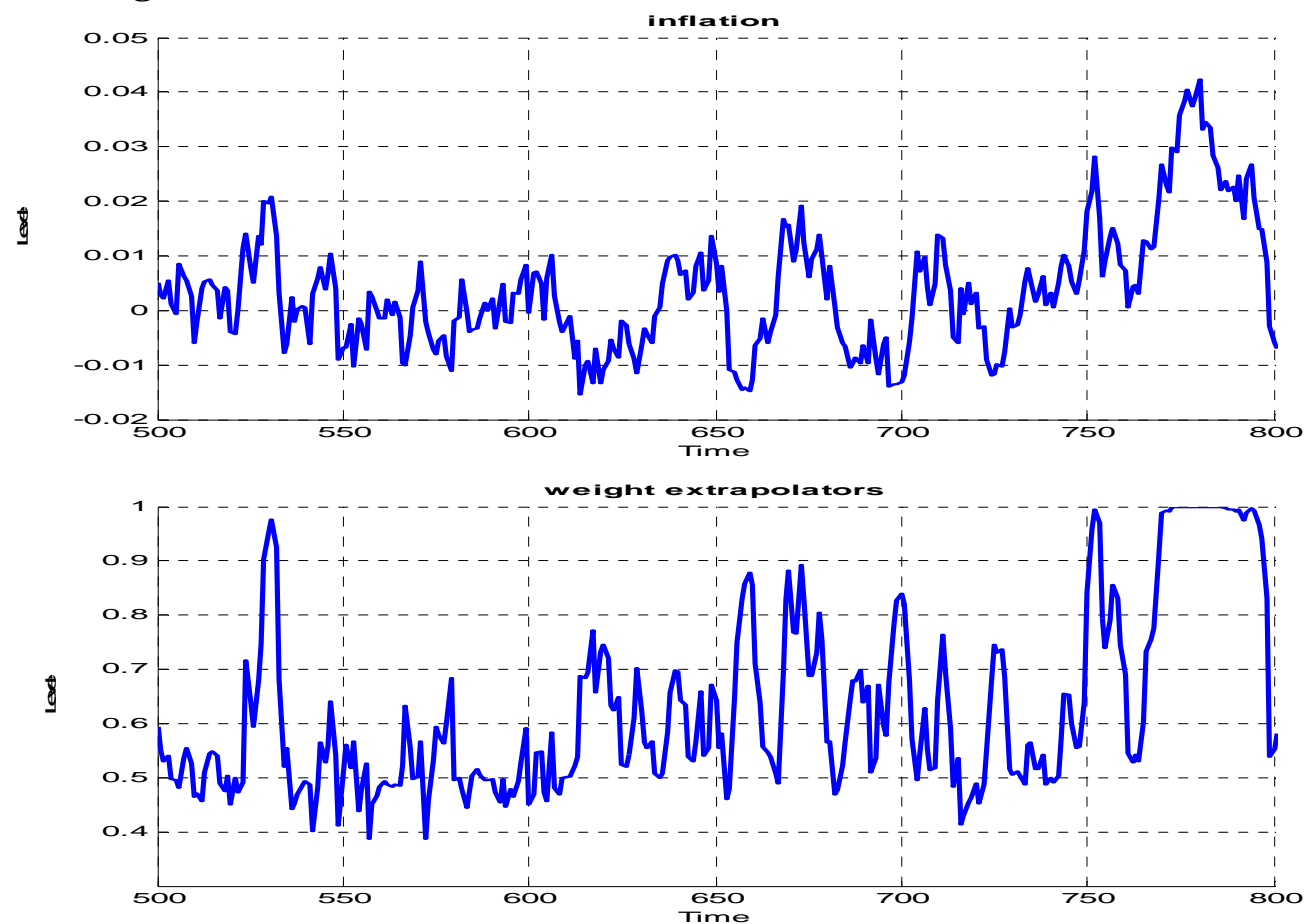
How can the central bank strengthen the inflation targeting regime? We take up this issue in sections 4 and 5 where we analyze the tradeoffs between output and inflation variability and the welfare implications.

\subsection{Impulse responses in the extended behavioral model}

In this section we present the impulse responses to a positive interest rate shock of one standard deviation. Two results stand out (see figure 6). First the uncertainty surrounding the effects of interest rate shocks is greater and lasts longer than in the simple behavioral model with homogenous inflation forecasting. Second, there is in this extended model considerably more inertia in inflation adjustment than in output adjustment following the interest rate shock. This feature whereby there is more inertia in inflation adjustment than in output adjustment after a shock is routinely found in VAR estimates of interest rate surprises. The inertia generated by the model finds its origin in the evolutionary process inherent in the fitness criterion guiding the selection of forecasting rules ${ }^{5}$.

\section{Figure 6: Mean impulse responses to an interest rate shock in the extended} behavioral model

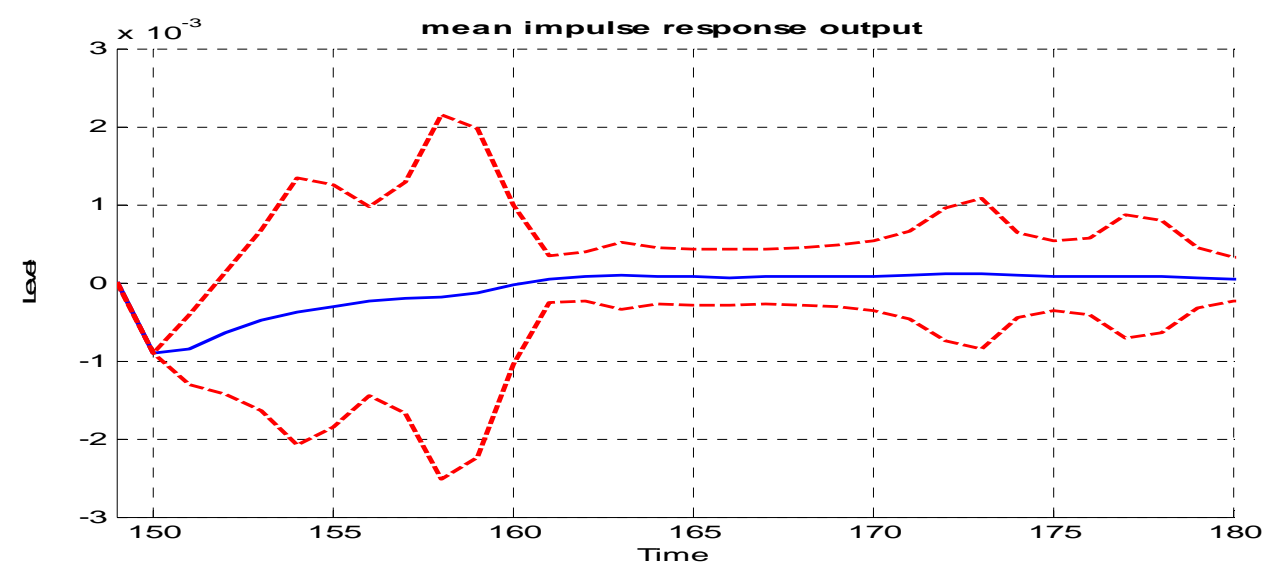

\footnotetext{
${ }^{5}$ A similar result was obtained by Anagastopoulos, et al. (2006)
} 

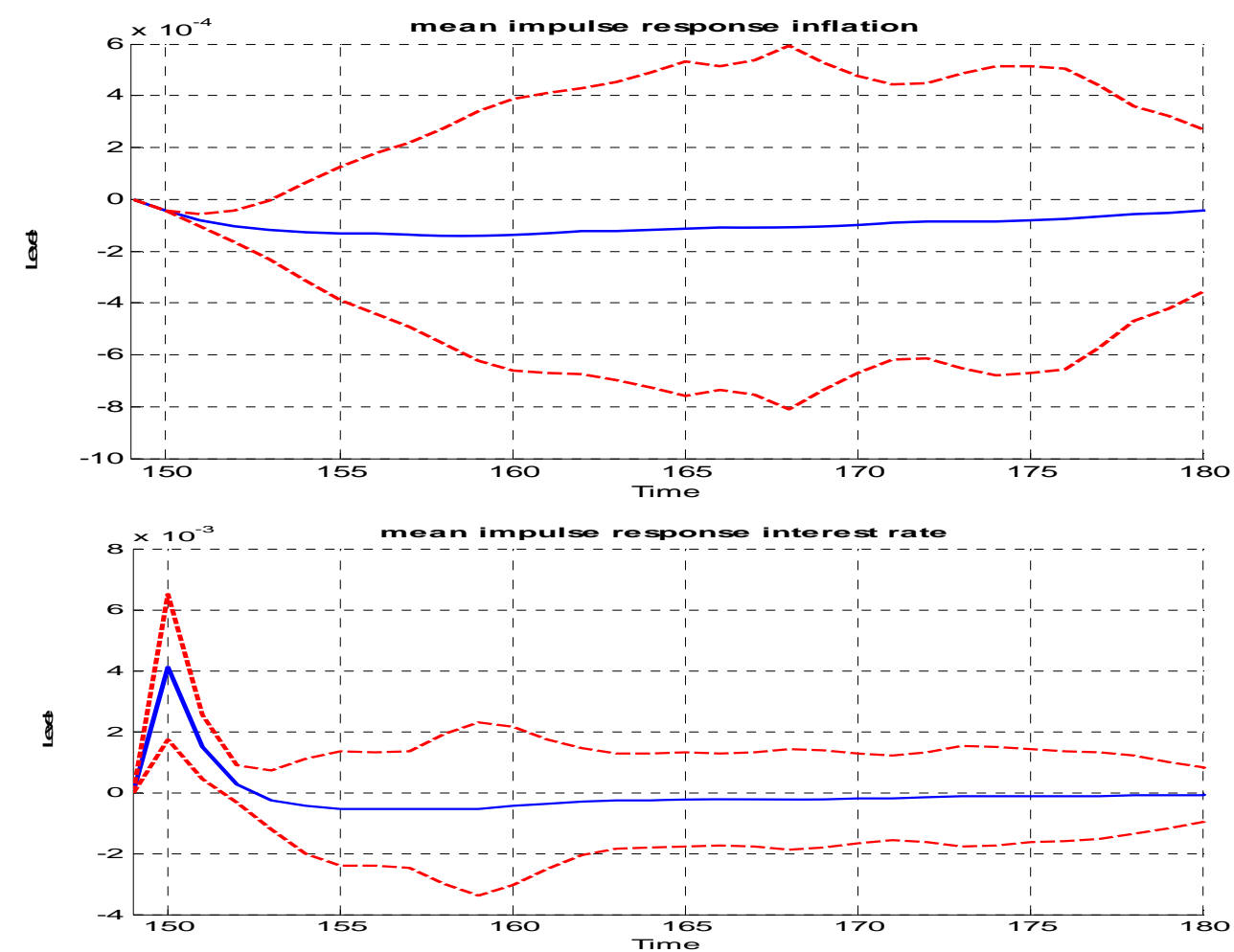

\subsection{Market sentiments and impulse responses}

An important finding of our model is the dependence of the impulse responses on the initial conditions. This implies that the transmission of shocks depends on the exact timing of these shocks. The reason is that "market sentiment" changes continuously thereby changing the transmission of these shocks.

There are two sources of "market sentiment" in the model. One originates with the waves of optimism and pessimism (animal spirits) produced by the switching dynamics between optimistic and pessimistic rules in forecasting output. The second one arises from the switches between the two inflation forecasting rules, producing periods of confidence in the inflation target announced by the central bank and periods of skepticism about this inflation target.

In this section we discuss with a few representative examples the nature of this dependence of the transmission mechanism on market sentiments. We start with presenting two impulse responses to the same interest rate shock (a one standard deviation increasing in the interest rate). These two shocks occur when the market sentiments are very different. We show the results in figure 7 . The left hand panel shows the impulse response of inflation to an interest rate increase that occurs when 
the market is skeptical about the announced inflation target. This can be seen by the fact that when the shock occurs (in period 100), almost all agents have become extrapolators, i.e. they have lost confidence in the inflation target. The right hand panel shows the impulse response when the interest rate shock occurs at a time when the weight of extrapolators is low. This is a regime characterized by confidence in the inflation target.

The results are striking. When the market is skeptical about the inflation target the interest rate shock has a substantial effect on inflation, while when the market exhibits confidence in the inflation target the same interest rate increase has only a very small effect on the rate of inflation. Conversely, since the impulse responses are symmetric, a decline in the interest rate has a strong positive effect on inflation when the market is skeptical and a weak effect on inflation when the market is confident in the inflation target. This result is akin to the stabilization bonus obtained in a fully credible inflation targeting regime.

\section{Figure 7: Impulse responses of inflation to interest rate shock (increase)}

Skepticism about inflation target
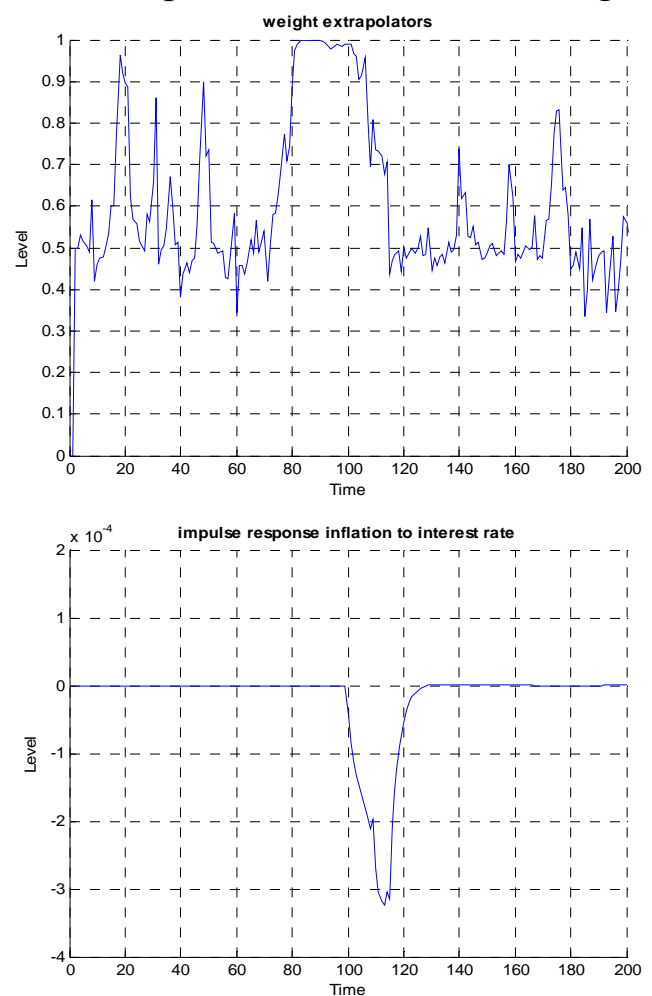

Confidence in inflation target
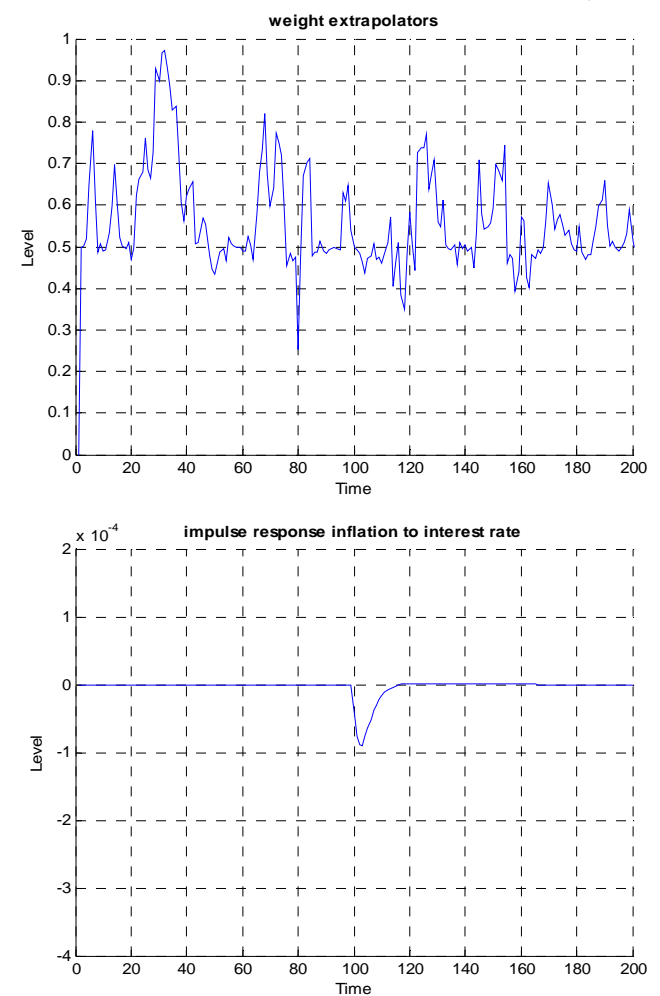
This dependence of the impulse responses on the market sentiments is also obtained when demand and supply shocks occur. We show an example involving a supply shock in figure 8 . The left hand panel exhibits the impulse response of output to a supply shock when the market sentiments about output growth are optimistic, while the right hand panel shows the same impulse response when the market sentiments are pessimistic. Again the results are striking. When optimists prevail a negative supply shock has a significantly lower and shorter-lived negative effect on output than when pessimists dominate the market.

Figure 8: Impulse responses of output to supply shock

Optimism
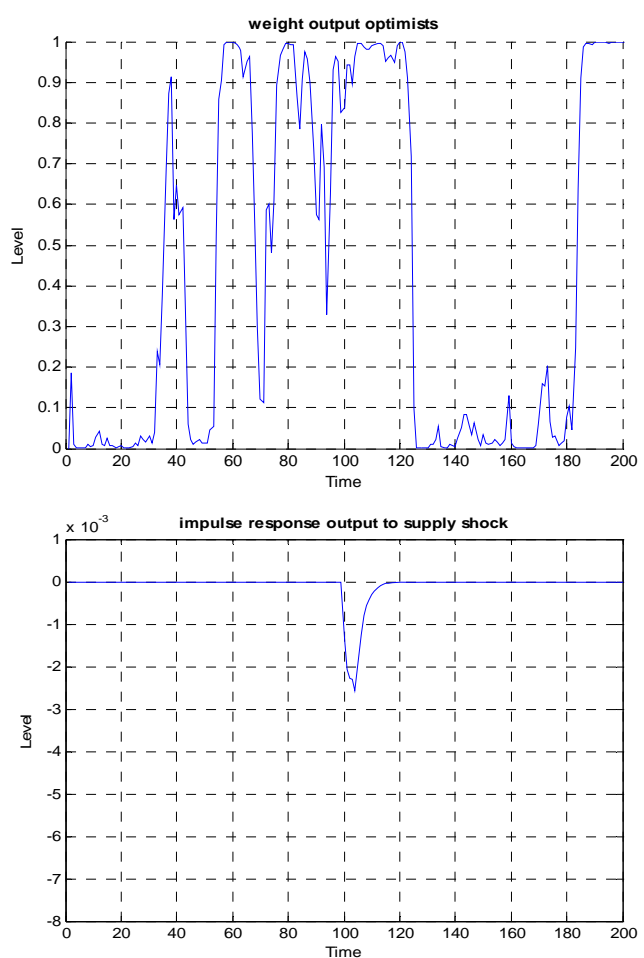

Pessimism
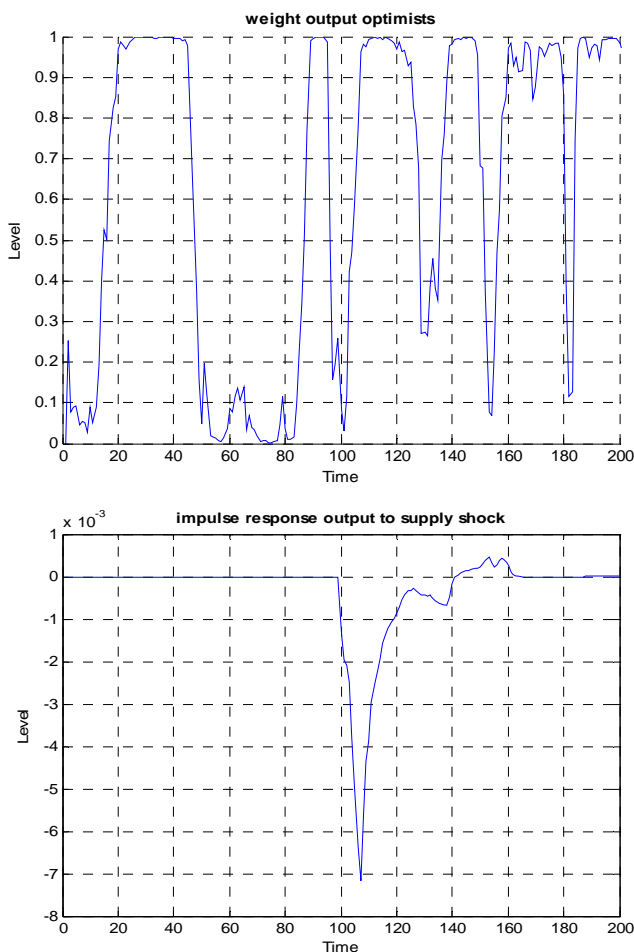

\section{Endogenous and exogenous inertia}

Business cycle movements in the DSGE-models arise as a result of exogenous shocks (in productivity and preferences) and lags in the transmission of these shocks to output and inflation. Thus inertia in output and inflation are the result of the lagged transmission of exogenous shocks. 
In a way it can be said that the lags in the transmission mechanism introduce an exogenous, some may say an ad-hoc, element into the logic of the DSGE-model. To give an example, Calvo pricing in which firms are constrained to adjust prices instantaneously (Christiano, Eichenbaum and Evans (2001)) is routinely imposed in DSGE models. It is clear, however, that such a restriction comes from outside the logic of the model. In a world where everybody understands the model and each other's rationality, which is at the core of the DSGE-models, agents would want to go immediately to the optimal plan using the optimal price. They would not want to accept such a restriction ${ }^{6}$.

One could call the inertia (and the business cycles) introduced in the DSGE-model exogenously created phenomena. In contrast, the behavioral model presented here is capable of generating inertia (and business cycles) without imposing lags in the transmission process. This could be called endogenous inertia. We illustrate this difference by analyzing the behavioral and the rational model in the absence of lags in the transmission process in the demand and the supply equations. We achieve this by setting the parameters of the forward looking variables $a_{1}=1$ in equation (1) and $b_{1}=$ 1 in equation (2). We then applied the same i.i.d. shocks in both the behavioral and the rational model and computed the autocorrelation coefficients of the simulated series of output gaps and inflation. We show the results in table 2. We observe that the behavioral model produces inertia (positive autocorrelation) in the output gap and in inflation even if there are no lags in the transmission of shocks. Our rational model produces no inertia in the output gap and in inflation.

Table 2 also shows the autocorrelation coefficients obtained in models that assume lags in the transmission. These coefficients are obtained when we set $a_{1}=0.5$ in equation (1) and $b_{1}=0.5$ in equation (2). These are also the numerical values assumed in all the simulations reported in the previous sections. We now observe that inertia in the output gap and in inflation increases in both models. However, it can be concluded that all of the inertia obtained in the rational model is the result of the lags in the

\footnotetext{
${ }^{6}$ The use of Calvo-pricing rules is often justified by invoking institutional restrictions that limit the freedom of action of individual firms. The question arises why rational and perfectly informed agents would accept institutions that limit their freedom to set optimal plans. After all, it is against their own interest to accept such limitations. It is not only against the interests of the firms, but also of consumers and workers, who in the rational macroeconomic models are agents who perfectly understand the world and their own interests and will always want to optimize their utilities. Any limitation on their optimizing behaviour reduces their welfare.
} 
transmission process. This is not the case in the behavioral model where most of the inertia is produced endogenously.

We also note from table 2 that even when the coefficients $a_{1}$ and $b_{1}$ of the forward looking variables of the model are set at 0.5 , the rational model produces less inertia than the behavioral model. We explore the sensitivity of the autocorrelation coefficients to these parameters more exhaustively in figure 9. This shows the autocorrelation coefficients as a function of $a_{1}$ and $b_{1}$. We observe that in the behavioral model the autocorrelation coefficients are not very sensitive to the $\mathrm{a}_{1}$ and $b_{1}$. This contrasts a great deal with the results of the rational model, where the sensitivity is very high. When $a_{1}$ and $b_{1}$ are close to 1 (i.e. no or weak lags in the transmission) the autocorrelation coefficients are very low (very low inertia). In order to produce inertia in the rational model which is of the same magnitude as in the behavioral model, $\mathrm{a}_{1}$ and $\mathrm{b}_{1}$ must be smaller than 0.5 .

This difference between the two models is quite fundamental. In the rational model there is no uncertainty about how the shock is transmitted in the model. Thus in the absence of lags in the transmission, agents immediately find the optimal levels of output and inflation. In order to produce the required inertia (and the business cycle movements), lags in the transmission preventing instantaneous adjustment to the optimal plan, are necessary. In the behavioral model, agents do not fully understand how the shock will be transmitted. As a result they follow a procedure (heuristics together with a selection mechanism) that functions very much like a "trial and error" mechanism aimed at revealing the information about shocks and the transmission process. This is a slow process that also uses backward evaluation processes. It generates an endogenous inertia (and business cycle) into the model.

The inertia obtained in our behavioral model could also be called informational inertia. In contrast to the rational expectations model, agents in the behavioral model experience an informational problem. They do not do not fully understand the nature of the shock nor its transmission. It takes time for them to understand. This cognitive problem then creates the inertia in output and prices. Thus we obtain very different theories of the business cycles in the two models $^{7}$

\footnotetext{
${ }^{7}$ Critics of the heuristic model presented here may argue that the comparison between the rational and the heuristic model is unfair for the rational model. Indeed the heuristic model generates inertia because the evaluation and selection process of the different heuristics is backward looking. This is the
} 
These differences also have policy implications. In the DSGE-models now favoured by central banks, business cycle movements in output and prices originate from price and wage stickiness. In order to reduce this kind of volatility more flexibility in prices and wages is required. That's why many central banks call for more flexibility. In a more flexible world, central banks will not be called upon so often to stabilize output, and thereby set price stability at risk.

In our behavioral model, business cycle movement in output arise from informational lags. Thus, even if prices and wages become more flexible, this will not necessarily reduce the business cycle movements in output. As a result, society's desire to stabilize output will not be reduced. And central banks that inevitably respond to these desires will face the need to stabilize output at the risk of reducing price stability.

Table 2: Autocorrelation coefficients in output gap and inflation

\begin{tabular}{|c|c|c|}
\hline No lags in $\mathrm{t}$ & & \\
\hline & behavioral model & rational model \\
\hline output gap & 0.77 & 0.07 \\
\hline inflation & 0.69 & -0.02 \\
\hline Lags in tran & & \\
\hline & behavioral model & rational model \\
\hline output gap & 0.89 & 0.79 \\
\hline inflation & 0.90 & 0.61 \\
\hline
\end{tabular}

Note: the autocorrelation coefficients are the averages obtained from simulating the model 1000 times, each time over 1000 periods.

reason why the heuristic model does not need lags in the transmission process to generate inertia. However, we claim that this evaluation and selection process can only be backward looking, and as a result, the lags that are present in the heuristic model are within the logic of that model. This contrasts with the lags introduced in the rational model: they come from outside the model. See Milani(2007b) who makes a similar point contrasting rational expectations models with learning models. 
Figure 9: Autocorrelation coefficients of output gap and inflation
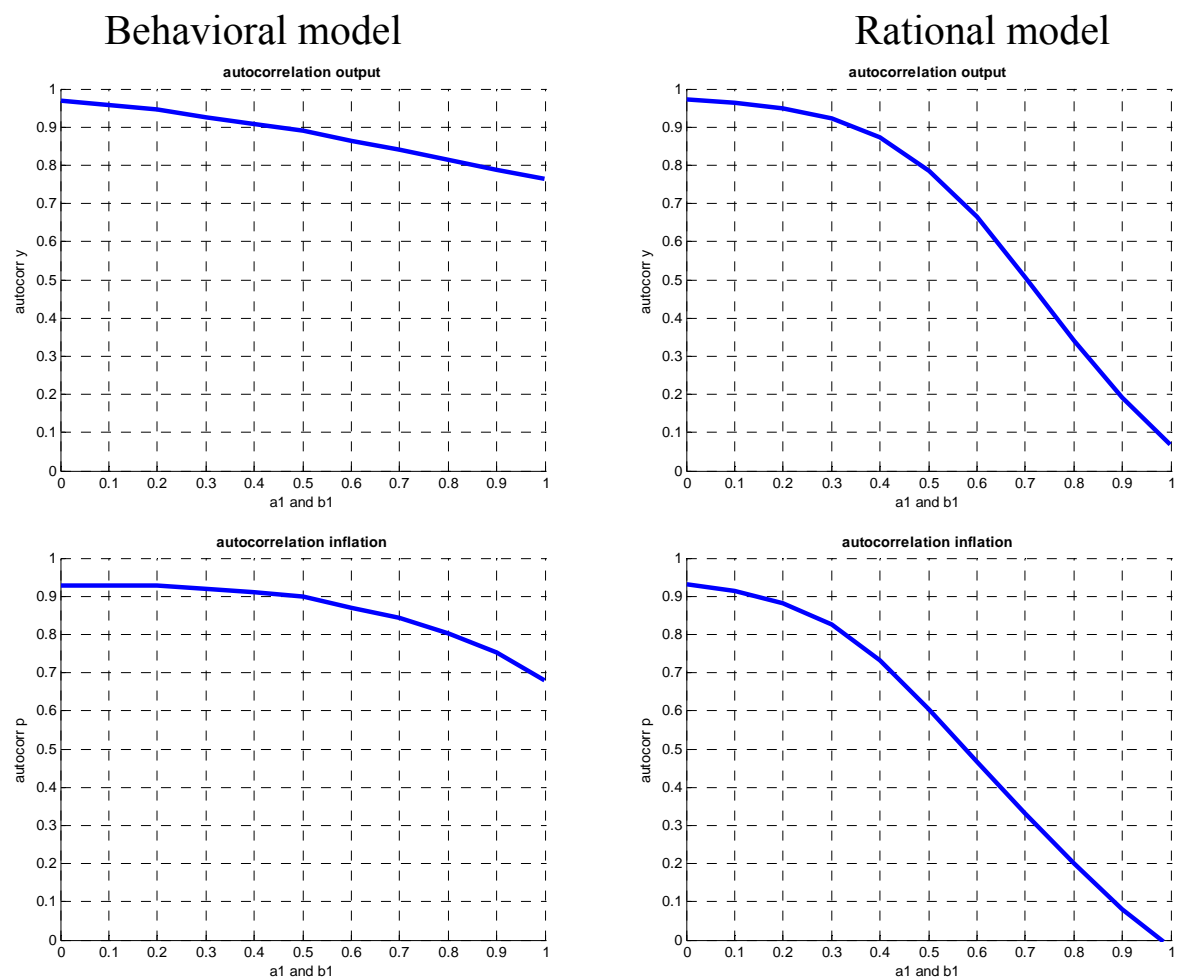

Note: see note of table 1 ; we have always set $a_{1}=b_{1}$

\section{Trade-offs between inflation and output variability}

In this section we analyze the tradeoff between output and inflation variability in the context of the extended behavioral model.

We construct the tradeoffs as follows. In figure 10 we show how output variability (panel a) and inflation variability (panel b) change as we increase the output coefficient $\left(c_{2}\right)$ in the Taylor rule from 0 to 1 . Each line represents the outcome for different values of the inflation coefficient $\left(c_{1}\right)$ in the Taylor rule.

Panel a showing the evolution of output variability exhibits the expected result, i.e. as the output coefficient increases (inflation targeting becomes less strict) output variability tends to decrease. One would now expect that this decline in output variability resulting from more active stabilization comes at the cost of more inflation variability. This, however, is not found in panel $b$. We observe that the relationship is non-linear. As the output parameter is increased from zero, inflation variability first declines. Only when the output parameter increases beyond a certain value (around $0.5)$ inflation variability starts increasing. Thus the central bank can reduce both 
output and inflation variability when it moves away from strict inflation targeting $\left(c_{2}=0\right)$ and engages in some output stabilization. Not too much though. Too much output stabilization turns around the relationship and increases inflation variability.

Figure 10: Output and inflation variability

Panel a

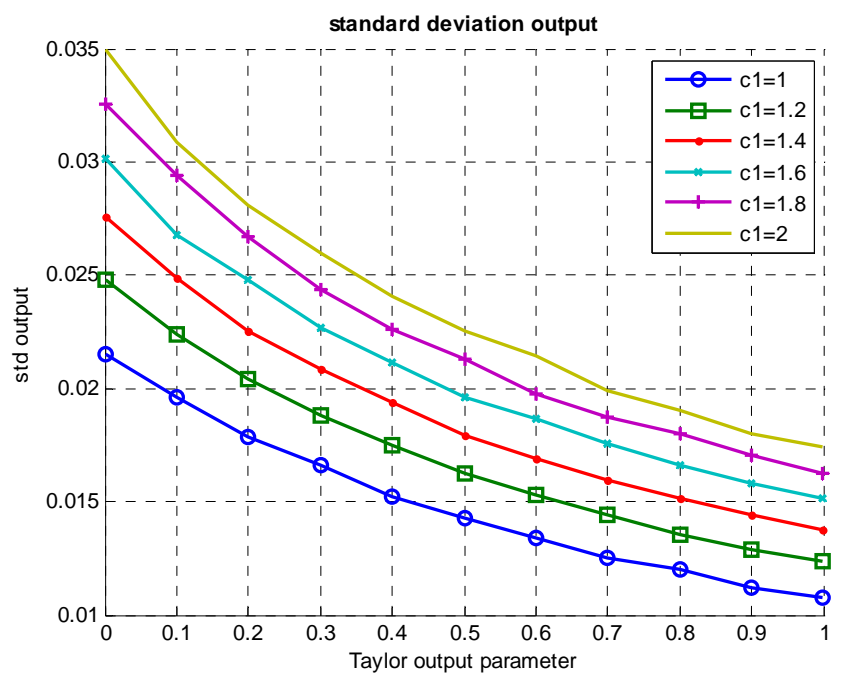

Panel b

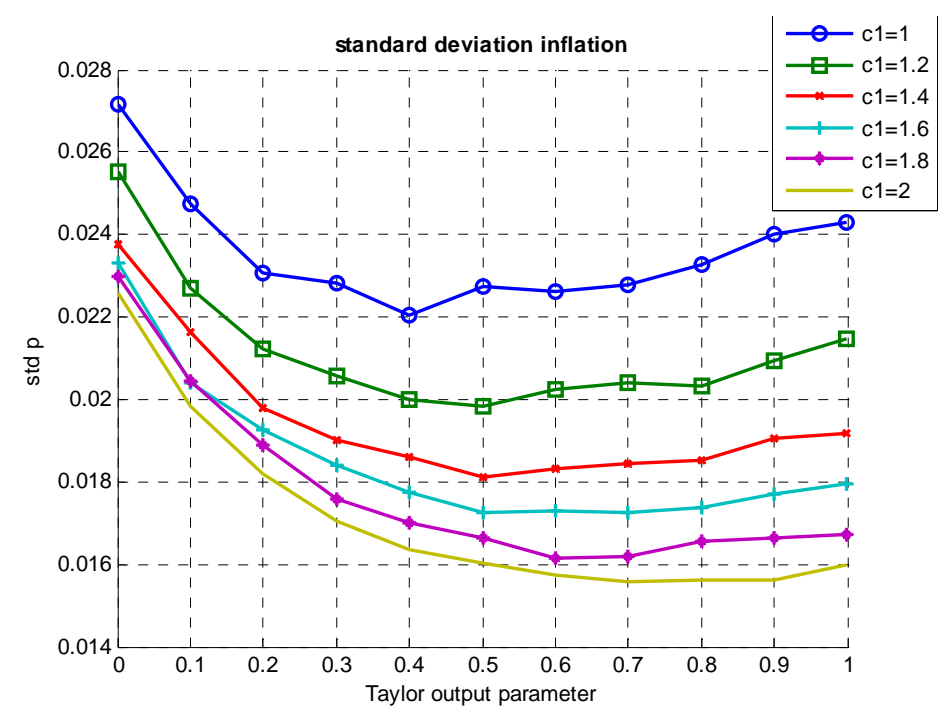

Figure 10 allows us to construct the tradeoffs between output and inflation variability. We show these in figure 11 for different values of the inflation parameter $c_{1}$. Take the tradeoff $\mathrm{AB}$. This is the one obtained for $\mathrm{c}_{1}=1$. We start from point $\mathrm{A}$ on the tradeoff. In point $A$, the output parameter $c_{2}=0$ (strict inflation targeting). As output stabilization increases we first move downwards. Thus increased output stabilization 
by the central bank reduces output and inflation variability. The relation is non-linear, however. At some point, with too high an output stabilization parameter, the tradeoff curve starts increasing, becoming a "normal" tradeoff, i.e. a lower output variability is obtained at the cost of increased inflation variability.

Note that increasing the inflation parameter in the Taylor rule has the effect of shifting the tradeoffs downwards, i.e. the central bank can improve the tradeoffs by reacting more strongly to changes in inflation ${ }^{8}$. Note, though that there is diminishing return in increasing the inflation parameter. When $\mathrm{c}_{1}$ comes close to 2 , further increases have a smaller impact on the tradeoffs.

Figure 11: Trade-offs in the extended behavioral model

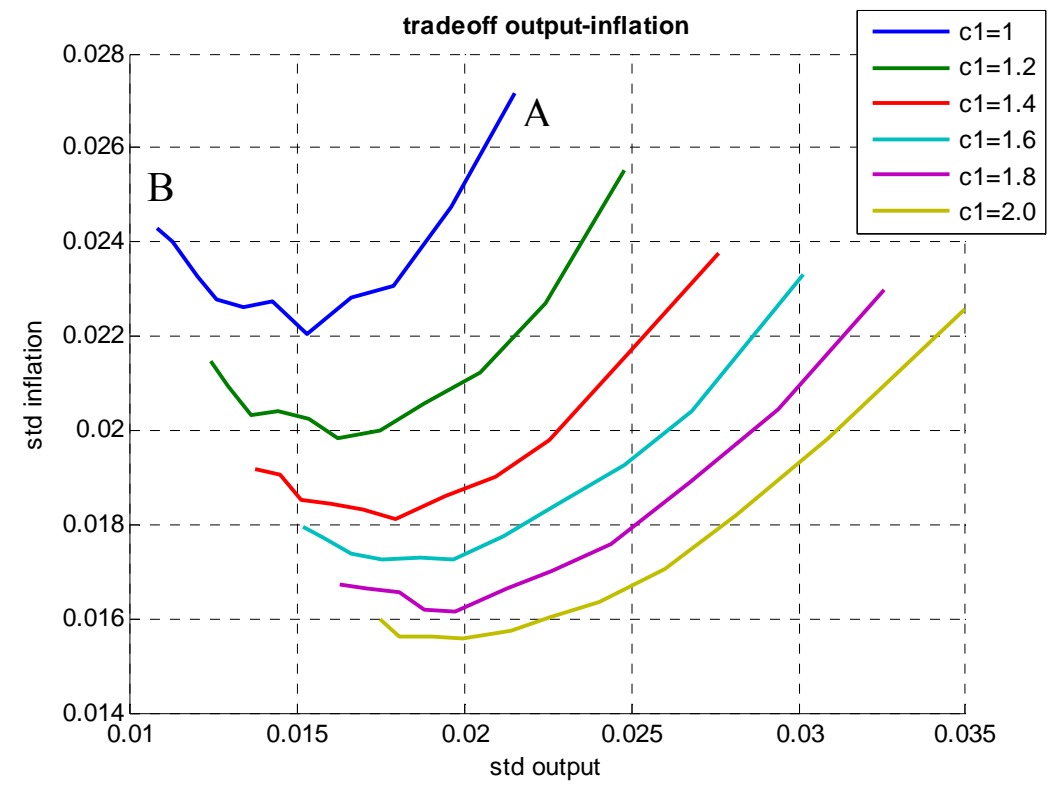

How can we interpret these results? Let's start from the case of strict inflation targeting, i.e. the authorities set $c_{2}=0$. There is no attempt at stabilizing output at all. The ensuing output variability intensifies the waves of optimism and pessimism (Animal spirits). These larges waves lead to higher inflation variability. Thus, some output stabilization is good; it reduces both output and inflation variability by preventing too large swings in animal spirits. With no output stabilization at all $\left(\mathrm{c}_{2}=0\right)$ the forces of animal spirits are so high that the high output variability also increases inflation volatility through the effect of the output gap on inflation (supply equation).

\footnotetext{
${ }^{8} \mathrm{~A}$ similar result on the importance of strict inflation is also found in Gaspar, Smets and Vestin(2006) who use a macromodel with statistical learning.
} 
Too much output stabilization, however, reduces the stabilization bonus provided by a credible inflation target. When the central bank attaches too much importance to output stabilization it creates more scope for better forecasting performance of the inflation extrapolators, leading to more inflation variability. .

These results are obtained in a regime in which inflation targeting is imperfectly credible. It may be useful to compare these with those obtained in a regime of perfect credibility of the inflation target. This is the regime which was implicit in the simple behavioral model of the previous section. We show the tradeoff obtained in this regime of perfect credibility in figure 12. The contrast with figure 11 is striking. Both the variability of inflation and output are now much lower. In addition, inflation variability is independent from output variability. In other words the tradeoffs are horizontal lines. (Note also that they are essentially the same for all values of the inflation coefficient in the Taylor rule). This result should not really be surprising. When inflation targeting is perfectly credible, the central bank profits from a stabilization bonus, allowing it to reduce output volatility without paying a price in terms of a higher inflation variability.

\section{Figure 12: Trade-offs in the simple behavioral model}

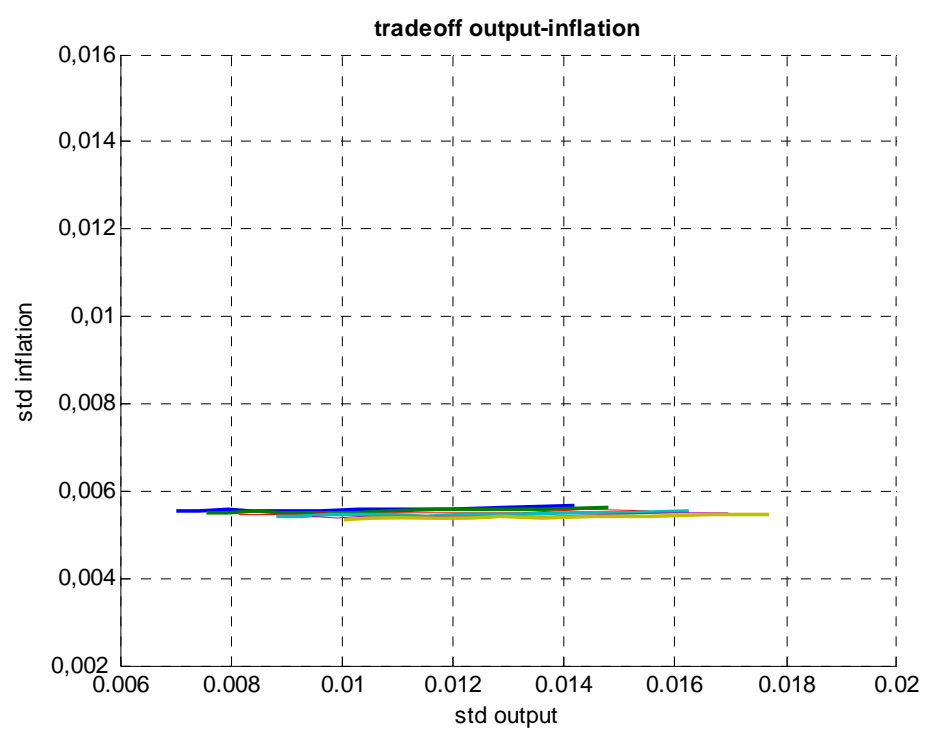

The comparison of figures 11 and 12 leads to the following conclusion. An inflation targeting regime that is $100 \%$ percent credible reduces the volatility of inflation and output dramatically. The fundamental reason is that it greatly reduces the scope for biased and correlated beliefs to create waves of optimism and pessimism that affect output and inflation. If inflation targeting is less than fully credible, these waves of 
optimism and pessimism are more difficult to control producing larger volatility of output and inflation. In such a regime active output stabilization helps to reduce output and inflation variability.

\section{Sensitivity analysis}

In this section we analyse how sensitive the results are to different numerical values of the "learning parameters" in the model. These are the parameters describing how agents use and select forecasting rules. There are three such parameters in our model. First, there is the divergence between the optimists' and pessimists' beliefs. We analyze the sensitivity to the coefficient $\beta$ in equation (6) which measures the sensitivity of the divergence of beliefs to output uncertainty.

Second, there is the memory agents have when calculating the performance of their forecasting. This was represented by the parameter $\omega_{k}$ in equations (9)-(10) and is a series of declining weights attached to past forecast errors. We define $\omega_{k}=(1-\rho) \rho^{k}$ (and $0 \leq \rho \leq 1$ ). The parameter $\rho$ can be interpreted as a measure of the memory of agents. When $\rho=0$ there is no memory; i.e. only last period's performance matters in evaluating a forecasting rule; when $\rho=1$ there is infinite memory.

Finally, there is the parameter $\gamma$ which measures the intensity with which agents are willing to switch to a better performing rule (see equations (11)-(12)).

We discuss the sensitivity of the results with respect to these parameters by showing how these parameters affect the volatility of inflation and output, and the degree of inertia (autocorrelation) in these variables.

\subsection{Sensitivity to divergence in beliefs}

The upper panels of figure 12 show how the volatility of output and inflation depends on the degree to which the divergence in beliefs depends on output volatility. We observe that when divergence increases, the volatility of output and inflation increases substantially. The lower panels of figure 12 indicate that increasing divergence tends to increase inertia in output (autocorrelation), with little effect on inflation inertia. 
Figure 12: Standard deviation and autocorrelation of output gap and inflation
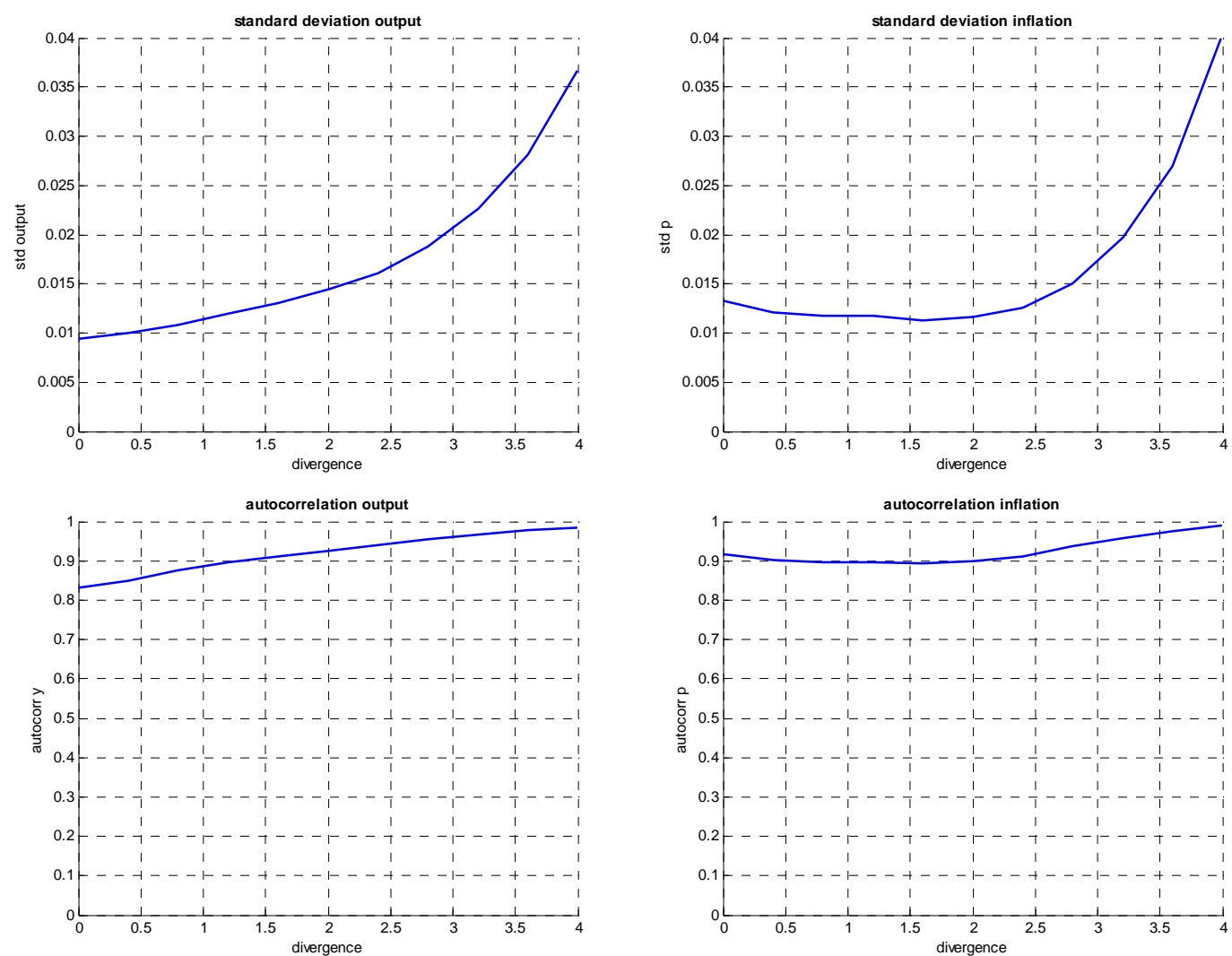

Note: the standard deviations and autocorrelation coefficients are the averages obtained from simulating the model 1000 times, each time over 1000 periods.

\subsection{Sensitivity to memory}

The memory agents use when they evaluate their past performance, plays an important role in the dynamics of the model. This is illustrated by figure 13 . The upper part shows the volatility of output and inflation for different values of the memory parameter $(\rho)$. It is striking to find that with increasing memory the volatility of these variables declines significantly. Note however that the relationship is nonlinear. One needs a large value of $\rho$ for the volatility to start declining. In the simulations presented in the previous sections we set $\rho=0.5$. The volatility obtained for this parameter value is very close to the volatility obtained when $\rho=0$ (i.e. when agents have no memory and only the performance of the last period).

We obtain similar results with the autocorrelation coefficients of output and inflation. For low and medium values of $\rho$ the autocorrelation coefficients are relatively constant. One needs a sufficiently large value of the memory parameter to reduce the 
autocorrelation coefficients significantly. We conclude that long memory tends to stabilize output and inflation and to reduce inertia in these variables.

\section{Figure 13: Standard deviation and autocorrelation of output gap and inflation}
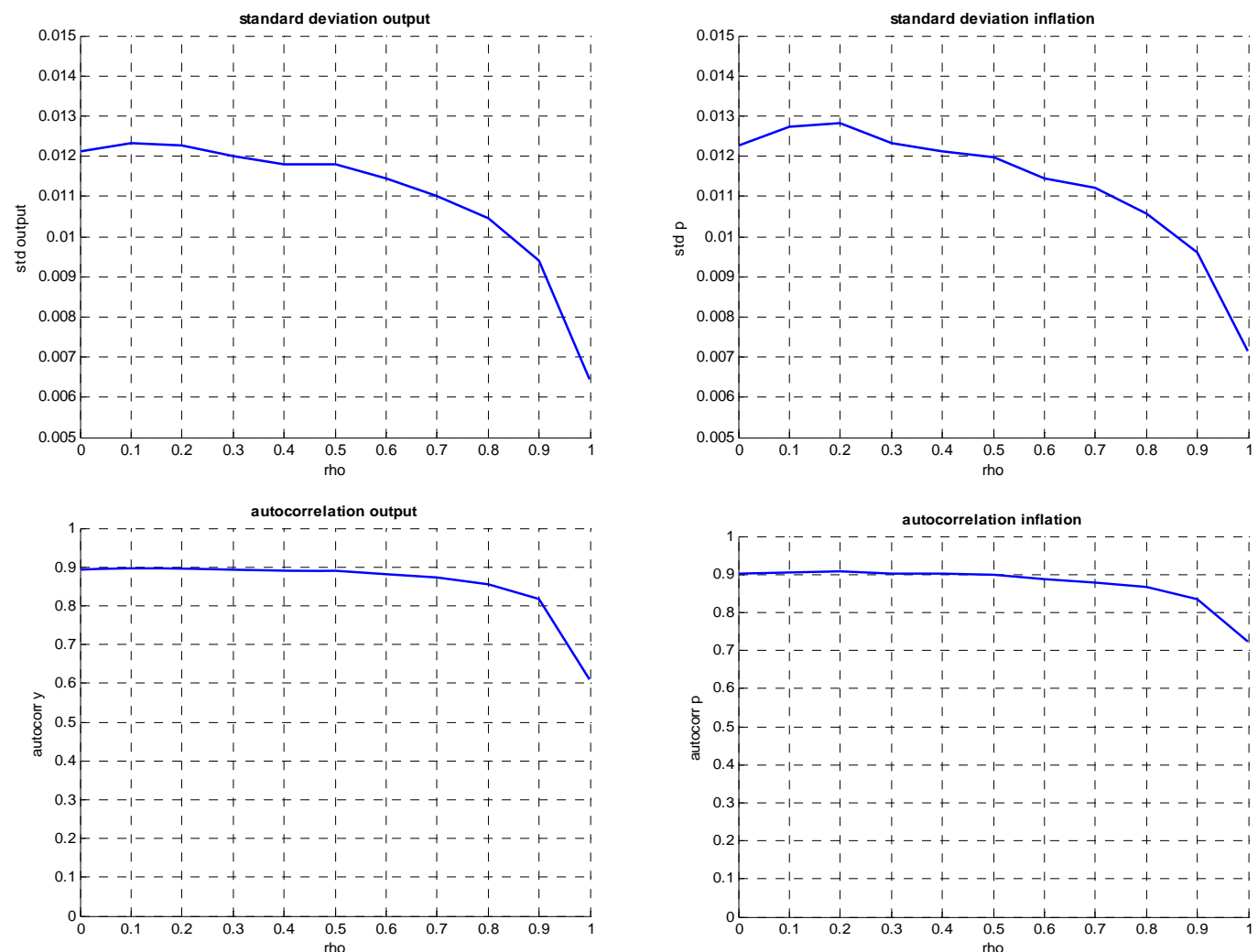

Note: the standard deviations and autocorrelation coefficients are the averages obtained from simulating the model 1000 times, each time over 1000 periods.

\subsection{Sensitivity to intensity of choice}

The intensity of choice parameter controls the degree with which agents switch from one rule to the other when the performance of the forecasting rules change. In general we find that, as this parameter increases, volatility and inertia tend to increase. This is illustrated in figure 14. The upper panel shows the volatility of output and inflation as a function of the intensity of choice parameter. We observe a clear positive relation. The lower panel shows how the autocorrelation coefficients increase when intensity of choice is increased.

We conclude that as agents react more forcefully to changes in performance of their forecasting rules, the volatility of output and inflation and their inertia increases. 
Figure 14: Standard deviation and autocorrelation of output gap and inflation
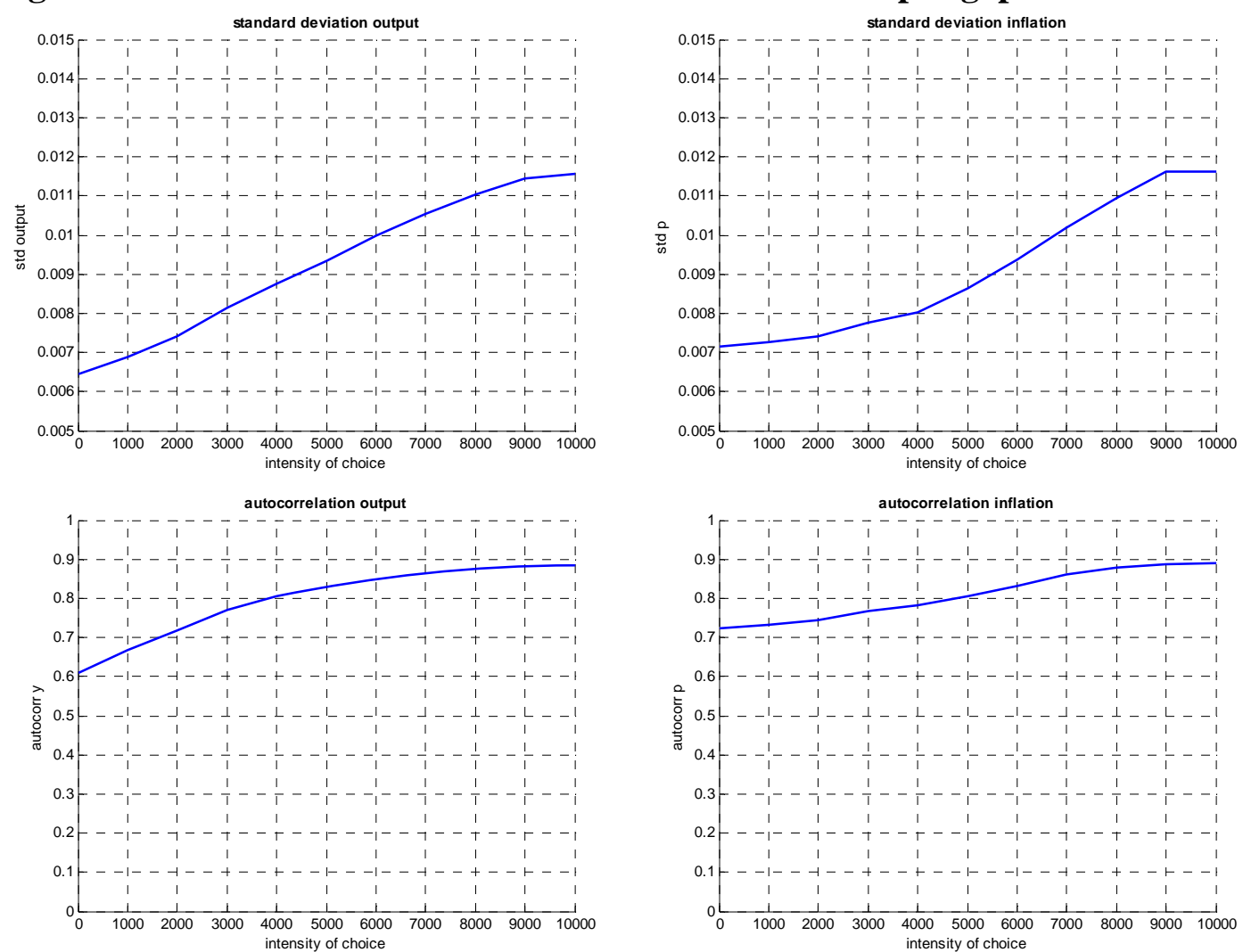

Note: the standard deviations and autocorrelation coefficients are the averages obtained from simulating the model 1000 times, each time over 1000 periods.

\section{Steady state properties of the model}

In this section we analyze the steady state properties of the model. We do this by mapping the space of attractors in the following way. First, we set all stochastic variables equal to zero. Second, we give an initial shock to output gap and inflation, respectively and we collect the attractor(s) to which the model converges. We repeat this exercise for different values of the Taylor rule parameters (c1 and c2). We show the results in figure 15, which 15 shows the attractors for the output gap. On the horizontal $\mathrm{x}$-axis we present the initial disturbance given to the output gap. On the horizontal $\mathrm{y}$-axis we show the different values of $\mathrm{c} 2$ for which the attractors were computed. Finally the vertical axis shows the attractors, i.e. the values of the output gap to which that variable returns after the initial shock. We observe the following interesting results. In the case of (imperfect) credibility of inflation targeting, the output gap returns to a steady state value of 0 , whatever the initial shock. This is not the case when inflation targeting has no credibility. In that case we have two types of attractors. A fixed attractor equal to zero to which the output gap returns if the initial 
shock is not too large, and a periodic attractor to which the output gap converges if the initial shocks is large enough. Thus when inflation targeting has no credibility a sufficiently large enough disturbance will force the output gap on a cyclical path of booms and busts. We show an example of such a path in figure 16

Figure 15 also reveals an interesting aspect of the effects of output stabilization as measured by the coefficient $\mathrm{c} 2$. We observe that as $\mathrm{c} 2$ increases the space of fixed point attractors increases, and the amplitude of the cyclical movements in the output gap declines. We explore this feature further in figure 17 which shows the phase diagram of the output gap when it has converged to the periodic attractor. We show these phase diagrams for increasing values of $\mathrm{c} 2$. It can be seen that the phase diagrams shrink with increasing values of $\mathrm{c} 2$. For values of $\mathrm{c} 2$ of 0.6 or higher the output gap converges to a fixed attractor equal to 0 .

Figure 15: Steady state attractors of the output gap

Imperfect credibility

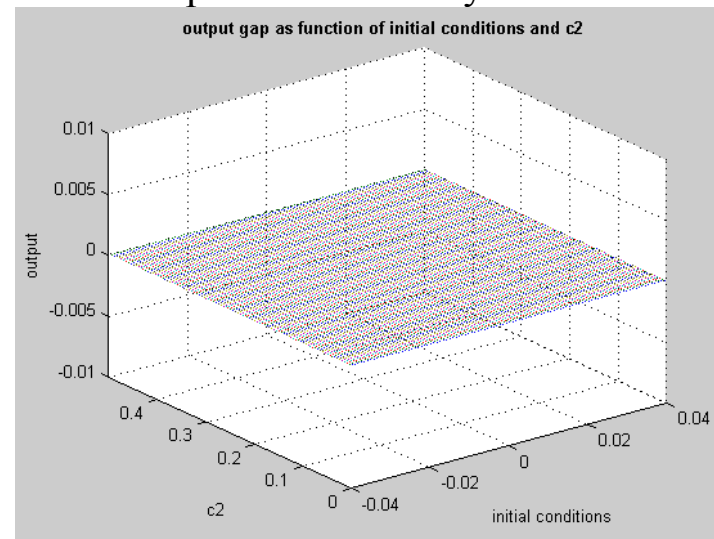

No credibility

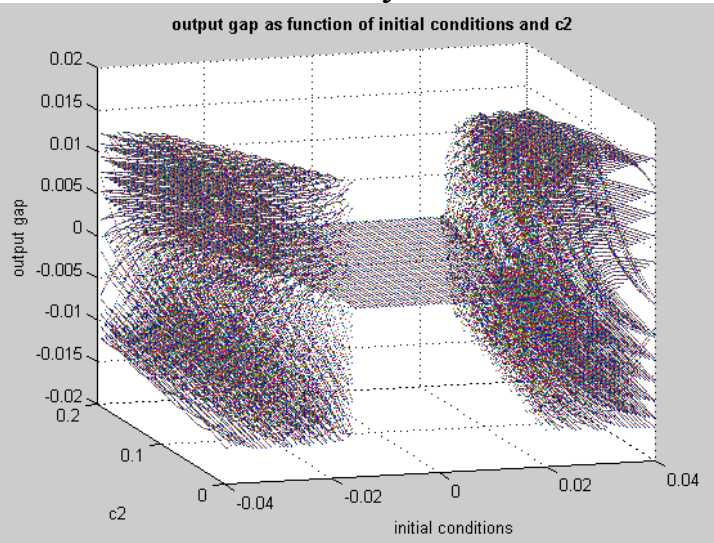

Figure 16: Cyclical movements of output in a deterministic simulation after an initial shock of $+0.03(\mathrm{c} 1=1.5$ and $\mathrm{c} 2=0.2)$

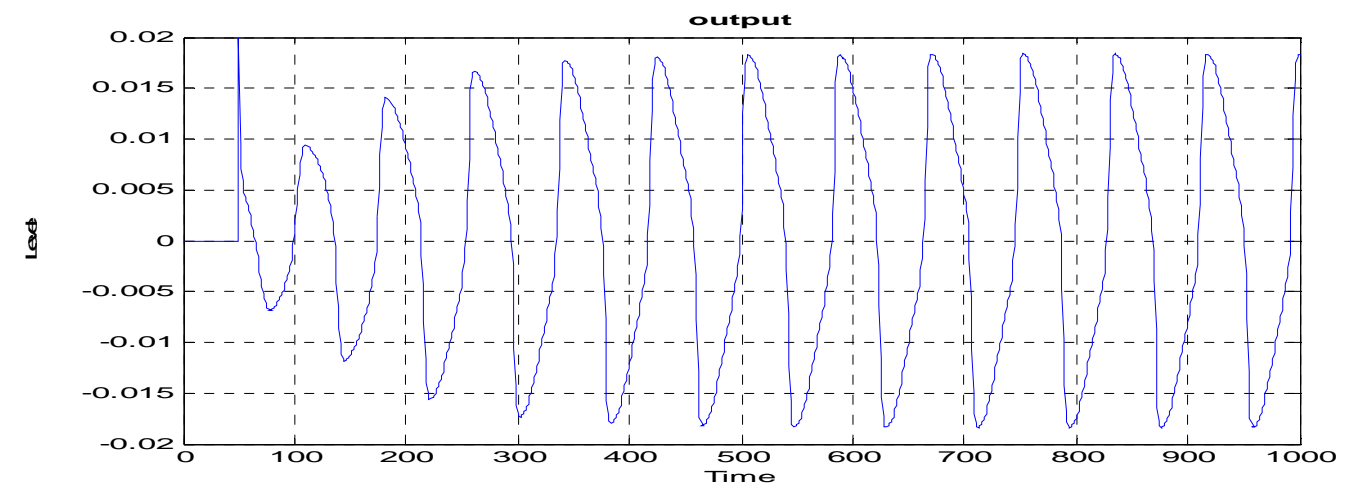


Figure 17: Phase diagrams of the output gap (no credibility)
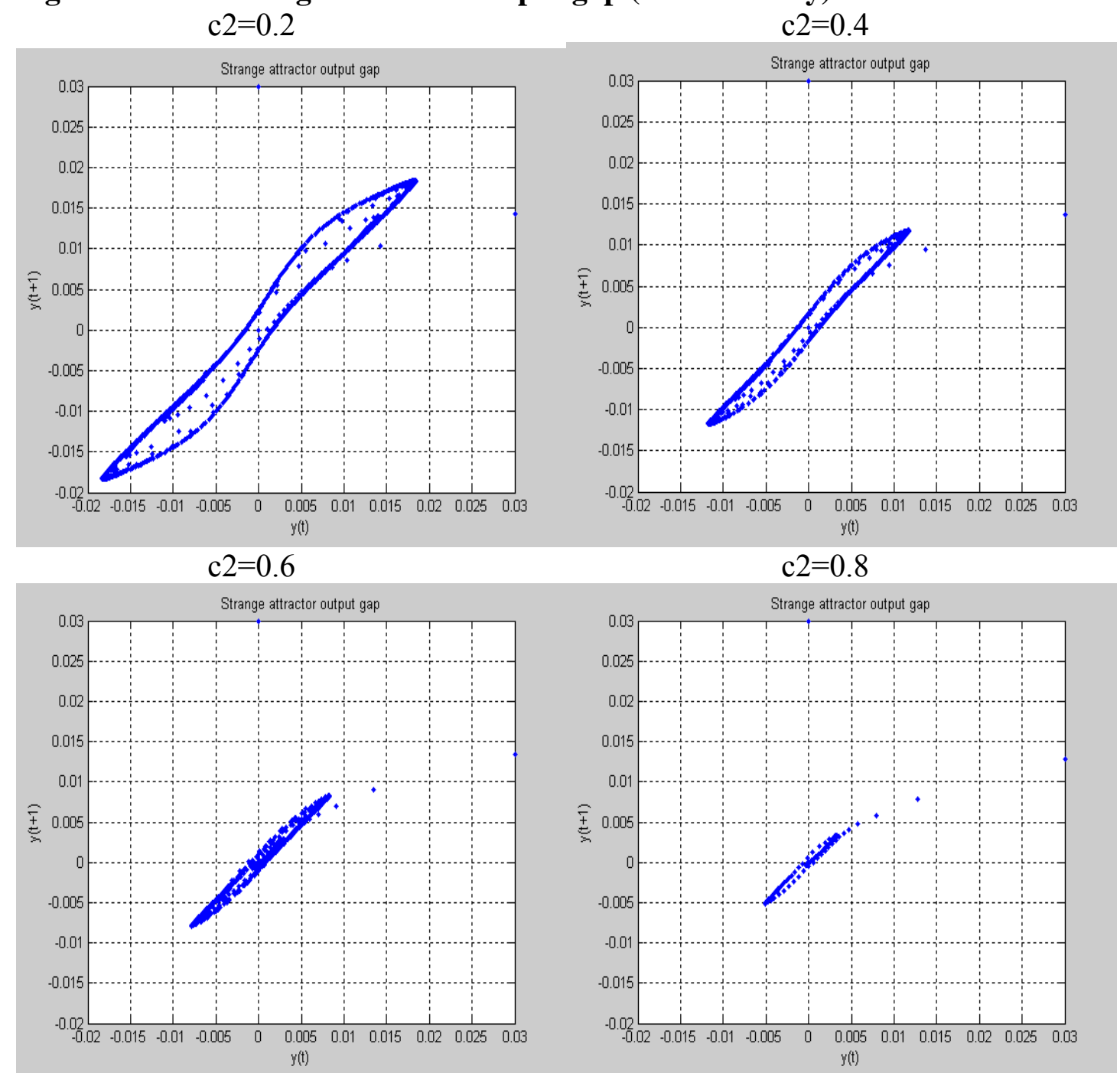

We repeated a similar exercise for inflation and obtained very similar results. They are shown in appendix $b$.

\section{Conclusion}

The idea that the business cycle is driven by waves of optimism and pessimism has a long tradition. It was made popular by Keynes who called these waves "animal spirits". Outside academia, this idea continues to enjoy a wide acceptability in explaining movements in economic activity.

As a result of the systematic incorporation of rational expectations in macroeconomic theory the idea that waves of optimism and pessimism can have an independent influence on economic activity has been discarded from academic thinking. The 
DSGE-models which have now achieved a near monopoly in macroeconomics, view business cycles as the result of a combination of exogenous shocks and slow transmission of these shocks into output and prices. In these models there is no place for endogenously generated business cycles.

The problem of the DSGE-models (and more generally of macroeconomic models based on rational expectations) is that they assume extraordinary cognitive capabilities of individual agents. Recent developments in other disciplines including psychology and brain science document that individual agents struggle with limited cognitive abilities, restricting their capacity to understand the world. As a result, individual agents use small bits of information and simple rules to guide their behaviour.

We have used these new insights to extend the DSGE-model framework to an environment in which agents use simple rules to forecast output and inflation. In order to provide discipline in the use of these rules we have introduced a mechanism that allows for the selection of those rules that are more profitable than others.

The ensuing "behavioral model" produces a number of results that distinguishes it from the rational expectations models. First, the behavioral model creates correlations in beliefs which in turn generate waves of optimism and pessimism. The latter produce endogenous cycles which are akin to the Keynesian "animal spirits". Second, due to its non-linearity, the behavioral model produces a degree of uncertainty about the transmission of monetary policy shocks that is different from the uncertainty obtained in DSGE-models. In the latter linear models, uncertainty about the effects of monetary policy shocks arises only because of the lack of precision in the estimation of the structural parameters of the model. In the behavioral model there is an additional dimension to uncertainty. This is that the same policy shock can have different effects depending on the state of the economy, including the degree of optimism and pessimism agents have about the future. As a result, the effectiveness of policy shocks depends on the timing of these shocks. This is an insight not found in mainstream DSGE-models. True, the DSGE-models can potentially produce similar results. However, these have routinely been excluded by linearizing an otherwise nonlinear model. 
A third result is that the inflation targeting regime turns out to be of great importance to stabilize the economy in a behavioral model. In a regime in which inflation targeting is credible inflation and output variability are greatly reduced. The reason is that credibility also helps to reduce correlations in beliefs and the ensuing selffulfilling waves of optimism and pessimism. In a regime of imperfect credibility, these waves are more pronounced.

However, and fourth, strict inflation targeting is not an optimal policy. Some output stabilization (given a credible inflation target) also helps in reducing the correlation of biased beliefs thereby reducing the scope for waves of optimism and pessimism to emerge and to destabilize output and inflation..

Finally, our model provides for a very different theory of the business cycle as compared to the business cycle theory implicit in the DSGE-models. In the DSGEmodels now favoured by central banks, business cycle movements in output and prices arise because rational agents cannot adjust their optimal plans instantaneously after an exogenous disturbance. Price and wage stickiness prevent such instantaneous adjustment. As a result, these exogenous shocks produce inertia and business cycle movements.

In contrast to the rational expectations model, agents in the behavioral model experience an informational problem. They do not do not fully understand the nature of the shock nor its transmission. It takes time for them to understand. This cognitive problem then creates the inertia in output and prices. Thus we obtain a very different theory of the business cycles.

These differences also have policy implications. In order to reduce output volatility in the DSGE-models more flexibility in prices and wages is required. That's why many central banks call for more flexibility of wages and prices. In a more flexible world, central banks will not be called upon so often to stabilize output, and thereby set price stability at risk.

In our behavioral model, business cycle movement in output arise from informational lags. Thus, even if prices and wages become more flexible, this will not necessarily reduce the business cycle movements in output. As a result, society's desire to stabilize output will not be reduced. And central banks that inevitably respond to these desires will face the need to stabilize output at the risk of reducing price stability. 
The research presented in this paper should be considered to be preliminary. In order to be convincing as an alternative modeling strategy, a rigorous empirical evaluation of the model will be necessary, whereby the predictions of the model are confronted with the data. In addition, the menu of heuristics which is extremely small in this paper, will have to be broadened so that the selection of the "fittest" rules can occur using a wider pool of possible rules.

\section{References:}

Anagnostopoulos, A., Licandro, O., Bove, I., Schlag, K., (2007), An evolutionary theory of inflation inertia, Journal of the European Economic Association, 5, 433-443.

Adjemian, S., Darracq Pariès, M., Moyen, S., (2007), Optimal Monetary Policy in an Estimated DSGE-Model for the Euro Area, Working Paper, no. 803, European Central Bank.

Anderson, S., de Palma, A., Thisse, J.-F., 1992, Discrete Choice Theory of Product Differentiation, MIT Press, Cambridge, Mass.

Azariadis, C. "Self-Fulfilling Prophecies," (1981). Journal of Economic Theory, 25, 380-96.

Benhabib, Jess and Roger E. A. Farmer, (1994). "Indeterminacy and Increasing Returns", Journal of Economic Theory 63: 19-46.

Binder, M., and M.H. Pesaran, (1996), Multivariate Rational Expectations Models and Macroeconomic Modeling: A Review and Some Results, in M.H. Pesaran and M. Wickens, eds., Handbook of Applied Econometrics: Macroeconomics.

Branch, W., and Evans, G., (2006), Intrinsic heterogeneity in expectation formation, Journal of Economic theory, 127, 264-95.

Brazier, A., Harrison, R., King, M., and Yates, T; (2006), The danger of inflating expectations of macroeconomic stability: heuristic switching in an overlapping generations monetary model, Working Paper no. 303, Bank of England, August.

Brock, W., and Hommes, C., 1997, A Rational Route to Randomness, Econometrica, $65,1059-1095$

Camerer, C., Loewenstein, G., Prelec, D., (2005), Neuroeconomics: How neurosciencecan inform economics, Journal of Economic Literature, 63(1), 964.

Christiano, L., Eichenbaum, M., and Evans, C., (2001), Nominal Rigidities and the Dynamic Effects of a Shock to Monetary Policy, NBER Working Paper, no. 8403, July.

Christiano, L., Motto, R., Rostagno, M., (2007), Shocks, Structures or Monetary Policies, Working Paper, no. 774, European Central Bank. 
Clarida, R., Gali, J., Gertler, M., (1999), The Science of Monetary Policy, A New Keynesian Perspective, Journal of Economic Literature, 37, 1661-1707.

Damasio, A., 2003, Looking for Spinoza, Joy, Sorrow and the Feeling Brain, Harcourt, 355p.

De Grauwe, P., and Grimaldi, M., (2006), The Exchange Rate in a Behavioral Finance Framework, Princeton University Press.

Della Vigna, S., (2007, Psychology and Economics: Evidence from the Field, NBER Working Paper, no. 13420.

De Long, J., Bradford, B., Schleiffer and Summers, L., 1990, "Noise Trader Risk in Financial Markets", Journal of Political Economy.

Estrella, A., and Furher, J., Dynamic Inconsistencies: Couterfactual Implications of a Class of Rational Expectations Models, American Economic Review, 92(4), Sept., 1013-1028.

Evans, G., and Honkapohja, S., 2001, Learning and Expectations in Macroeconomics, Princeton University Press, 421pp.

Farmer, Roger E. A. and Guo, J.-T., (1994). "Real Business Cycles and the Animal Spirits Hypothesis," Journal of Economic Theory 63, 42-73.

Farmer, Roger, E.A., (2006), Animal Spirits, Palgrave Dictionary of Economics.

Galí, J., López-Salido, D., Vallés, J., (2004), Rule of Thumb Consumers and the Design of Interest Rate Rules, Journal of Money Credit and Banking, 36, no. 4, 739-764.

Galí, J., (2008), Monetary Policy, Inflation and the Business Cycle, Princeton University Press, 203pp.

Gaspar, V., Smets, F., Vestin, D., (2006), Adaptive Learning, Persistence and Optimal Monetary Policy, Working Paper Series, no. 644, European Central Bank.

Gigerenzer, G., and P.M. Todd.1999. Simple Heuristics That Make Us Smart. New York: Oxford University Press.

Goodhart, C., (2007), The Continuing Muddles of Monetary Theory: A Steadfast Refusal to Face Facts,(mimeo), Financial Markets Group, London School of Economics

Hayek, F., (1945), The Use of Knowledge in Society, American Economic Review, XXXV, no. 4, 519-530..

Kahneman, D., and Tversky, A., 1973, Prospect Theory: An analysis of decisions under risk, Econometrica, 47, 313-327

Kahneman, D., and Tversky, A., 2000, Choices, Values and Frames, New York: Cambridge University Press.

Kahneman, D., 2002, Maps of Bounded Rationality: A Perspective on Intuitive Judgment and Choice, Nobel Prize Lecture, December 8, Stockholm

Kahneman, D., and Thaler, R., 2006, Utility Maximization and Experienced Utility, Journal of Economic Perspectives, 20, 221-234

Keynes, J. M. (1936): The General Theory of Employment, Interest and Money. MacMillan and Co. 
Mackowiak, B., and Wiederholt, (2005), Optimal Sticky Prices under Rational Inattention, Discussion Paper, Humboldt University, Berlin.

Milani, F., (2007a), Learning and Time-Varying Macroeconomic Volatility, mimeo, University of California, Irvine.

Milani, F., (2007b), Expectations, Learning and Macroeconomic Persistence, Journal of Monetary Economics, 54, 2065-2082.

Nelson, E., (1998), Sluggish Inflation and Optimizing Models of the Business Cycle, Journal of Monetary Economics, 42(2), Oct., 303-322.

Orphanides, A., and Williams, J., (2004), Robust Monetary Policy with Imperfect Information, Board of Governors of the Federal Reserve System.

Thaler, R., 1994, Quasi Rational Economics, Russell Sage Foundation, New York.

Sargent, T. 1993. Bounded Rationality in Macroeconomics. Oxford University Press.

Sims, C., (2005), Rational Inattention: A Research Agenda, Discussion Paper, no. 34/2005, Deutsche Bundesbank.

Smets, F. and Wouters, R., (2003), An Estimated Dynamic Stochastic General Equilibrium Model, Journal of the European Economic Association, 1, 11231175.

Smets, F., and Wouters, R., (2007), Shocks and Frictions in Us Business Cycles, Working Paper, no. 722, European Central Bank.

Stanovich, K., and West, R., 2000, Individual differences in reasoning: Implications for the rationality debate, Behavioral and Brain Sciences, 23, 645--665.

Svensson, L., (1997), Inflation Forecast Targeting: Implementing and Monitoring Inflation Targets, European Economic Review, 41: 111-46.

Tversky, A., and Kahneman, D., 1981, The framing of decisions and the psychology of choice, Science, 211, 453-458.

Walsh, C., (2003), Monetary Theory and Policy, MIT-Press, 612 pp.

Woodford, M., (2003), Interest and Prices: Foundations of a Theory of Monetary Policy, Princeton University Press. 


\section{Heuristic model}

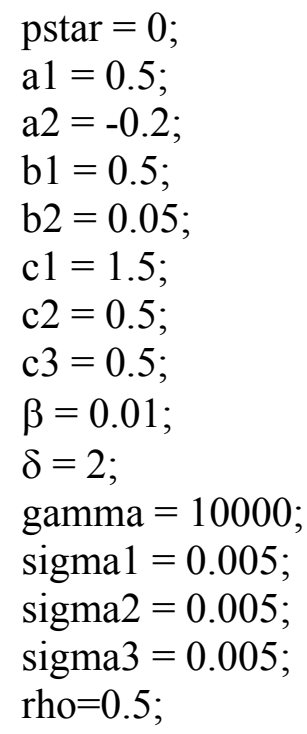

\section{Rational model}

$$
\begin{aligned}
& \text { pstar }=0 ; \\
& \text { a1 }=0.5 ; \\
& \text { a2 }=-0.2 ; \\
& \text { b1 }=0.5 ; \\
& \text { b2 }=0.05 \\
& \text { c1 }=1.5 ; \\
& \text { c2 }=0.5 ; \\
& \text { c3 }=0.5 ;
\end{aligned}
$$

sigma $1=0.005$

sigma $2=0.005$ sigma3 $=0.005$
$\%$ the central bank's inflation target

$\%$ coefficient of expected output in output equation

$\% \mathrm{a}$ is the interest elasticity of output demand

$\% \mathrm{~b} 1$ is coefficient of expected inflation in inflation equation

$\% \mathrm{~b} 2$ is coefficient of output in inflation equation

$\% \mathrm{c} 1$ is coefficient of inflation in Taylor equation

$\% \mathrm{c} 2$ is coefficient of output in Taylor equation

\%interest smoothing parameter in Taylor equation

$\%$ fixed divergence in beliefs

$\%$ variable component in divergence of beliefs

$\%$ switching parameter gamma in Brock Hommes

$\%$ standard deviation shocks output

\%standard deviation shocks inflation

$\%$ standard deviation shocks Taylor

$\%$ rho measures the speed of declining weights omega in mean squares errors

$\%$ the central bank's inflation target

$\%$ coefficient of expected output in output equation

$\%$ a is the interest elasticity of output demand

$\% \mathrm{~b} 1$ is coefficient of expected inflation in inflation equation

$\% \mathrm{~b} 2$ is coefficient of output in inflation equation

$\% \mathrm{c} 1$ is coefficient of inflation in Taylor equation

$\% \mathrm{c} 2$ is coefficient of output in Taylor equation

$\%$ interest smoothing parameter in Taylor equation

$\%$ standard deviation shocks output

$\%$ standard deviation shocks inflation

\%standard deviation shocks Taylor 
Appendix B: steady state attractors for inflation

Figure A1: Steady state attractors for inflation

Imperfect credibility

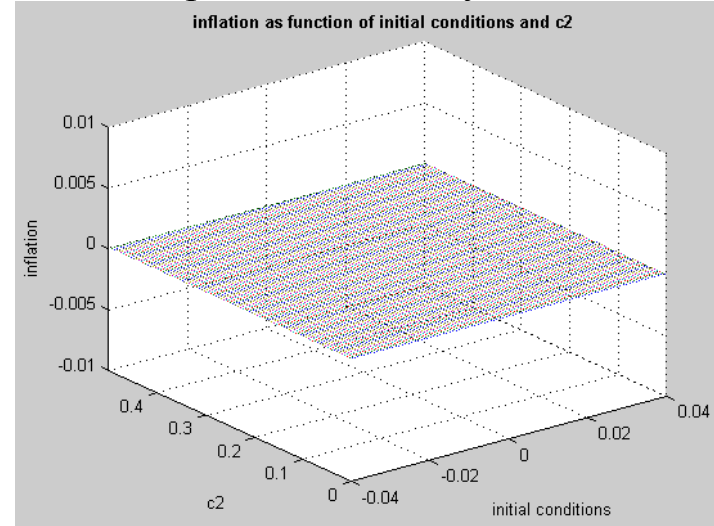

No credibility

inflation as function of initial conditions and $\mathrm{c} 1$

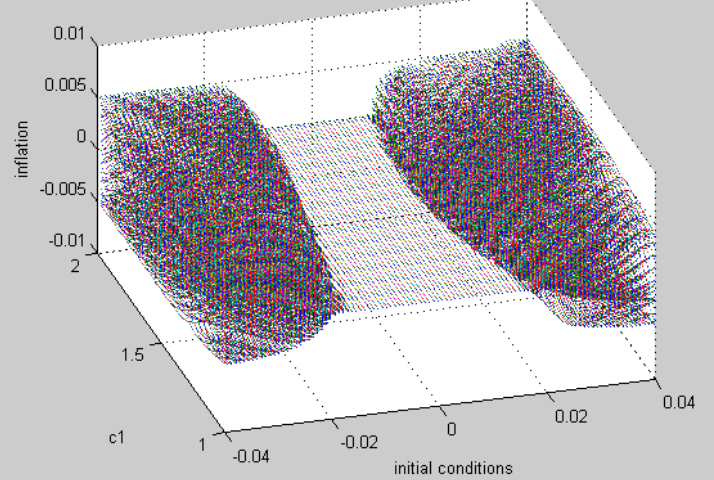

Figure A2: Phase diagrams of inflation (initial shock is 0.03; no credibility) $\mathrm{c} 2=0.2$

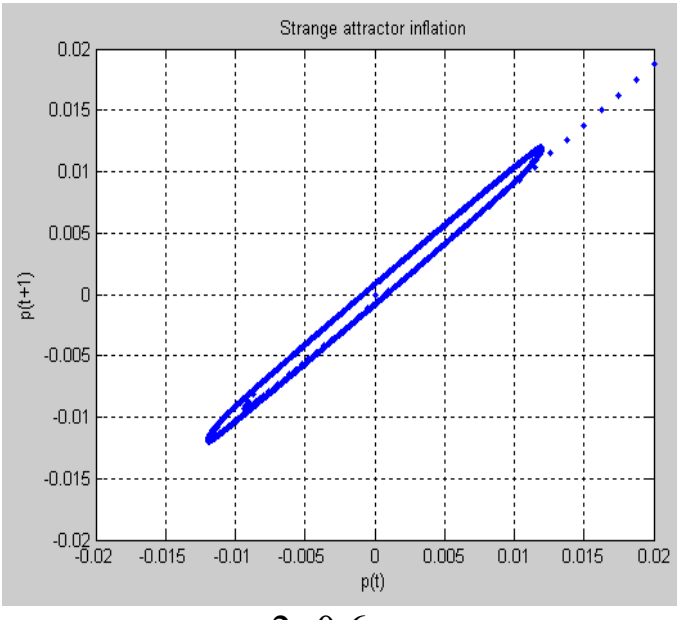

$\mathrm{c} 2=0.6$

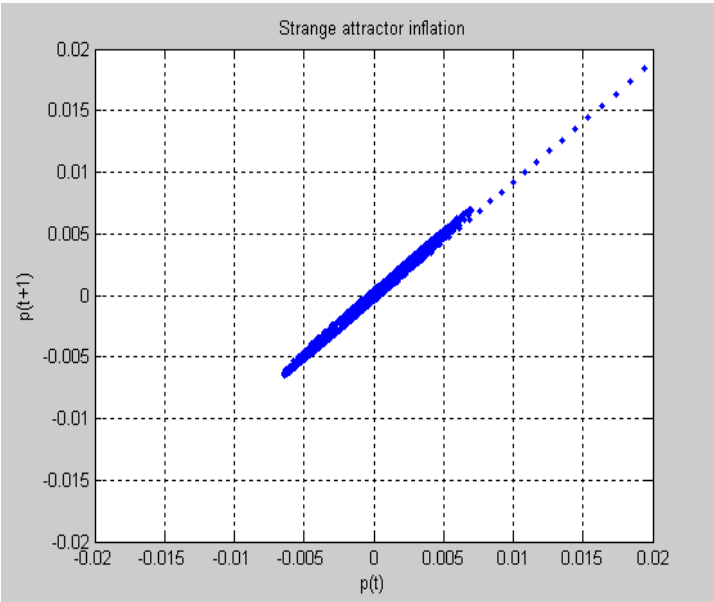

$\mathrm{c} 2=0.4$

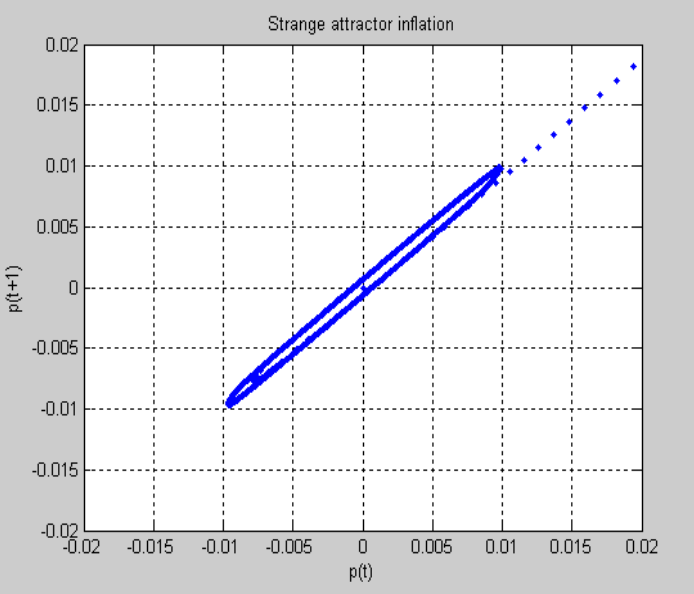




\section{CESifo Working Paper Series}

for full list see www.cesifo-group.org/wp

(address: Poschingerstr. 5, 81679 Munich, Germany, office@cesifo.de)

2357 Wolfgang Buchholz and Jan Schumacher, Discounting the Long-Distant Future: A Simple Explanation for the Weitzman-Gollier-Puzzle, July 2008

2358 Luca Anderlini, Leonardo Felli and Alessandro Riboni, Statute Law or Case Law?, July 2008

2359 Guglielmo Maria Caporale, Davide Ciferri and Alessandro Girardi, Are the Baltic Countries Ready to Adopt the Euro? A Generalised Purchasing Power Parity Approach, July 2008

2360 Erkki Koskela and Ronnie Schöb, Outsourcing of Unionized Firms and the Impacts of Labour Market Policy Reforms, July 2008

2361 Francisco Alvarez-Cuadrado and Ngo Van Long, A Permanent Income Version of the Relative Income Hypothesis, July 2008

2362 Gabrielle Demange, Robert Fenge and Silke Uebelmesser, Financing Higher Education and Labor Mobility, July 2008

2363 Alessandra Casarico and Alessandro Sommacal, Labor Income Taxation, Human Capital and Growth: The Role of Child Care, August 2008

2364 Antonis Adam, Manthos D. Delis and Pantelis Kammas, Fiscal Decentralization and Public Sector Efficiency: Evidence from OECD Countries, August 2008

2365 Stefan Voigt, The (Economic) Effects of Lay Participation in Courts - A Cross-Country Analysis, August 2008

2366 Tobias König and Andreas Wagener, (Post-)Materialist Attitudes and the Mix of Capital and Labour Taxation, August 2008

2367 Ximing Wu, Andreas Savvides and Thanasis Stengos, The Global Joint Distribution of Income and Health, August 2008

2368 Alejandro Donado and Klaus Wälde, Trade Unions Go Global!, August 2008

2369 Hans Gersbach and Hans Haller, Exit and Power in General Equilibrium, August 2008

2370 Jan P.A.M. Jacobs and Jan-Egbert Sturm, The Information Content of KOF Indicators on Swiss Current Account Data Revisions, August 2008

2371 Oliver Hülsewig, Johannes Mayr and Timo Wollmershäuser, Forecasting Euro Area Real GDP: Optimal Pooling of Information, August 2008 
2372 Tigran Poghosyan and Jakob de Haan, Determinants of Cross-Border Bank Acquisitions in Transition Economies: A Latent Class Analysis, August 2008

2373 David Anthoff and Richard S.J. Tol, On International Equity Weights and National Decision Making on Climate Change, August 2008

2374 Florian Englmaier and Arno Schmöller, Reserve Price Formation in Online Auctions, August 2008

2375 Karl Farmer, Birgit Friedl and Andreas Rainer, Effects of Unilateral Climate Policy on Terms of Trade, Capital Accumulation, and Welfare in a World Economy, August 2008

2376 Monika Bütler, Stefan Staubli and Maria Grazia Zito, The Role of the Annuity’s Value on the Decision (Not) to Annuitize: Evidence from a Large Policy Change, August 2008

2377 Inmaculada Martínez-Zarzoso, The Impact of Urbanization on $\mathrm{CO}_{2}$ Emissions: Evidence from Developing Countries, August 2008

2378 Brian Roberson and Dmitriy Kvasov, The Non-Constant-Sum Colonel Blotto Game, August 2008

2379 Ian Dew-Becker, How Much Sunlight Does it Take to Disinfect a Boardroom? A Short History of Executive Compensation Regulation, August 2008

2380 Cécile Aubert, Oliver Falck and Stephan Heblich, Subsidizing National Champions: An Evolutionary Perspective, August 2008

2381 Sebastian Buhai, Miguel Portela, Coen Teulings and Aico van Vuuren, Returns to Tenure or Seniority?, August 2008

2382 Erkki Koskela and Jan König, Flexible Outsourcing, Profit Sharing and Equilibrium Unemployment, August 2008

2383 Torberg Falch and Justina AV Fischer, Does a Generous Welfare State Crowd out Student Achievement? Panel Data Evidence from International Student Tests, September 2008

2384 Pedro Gomes and François Pouget, Corporate Tax Competition and the Decline of Public Investment, September 2008

2385 Marko Koethenbuerger, How Do Local Governments Decide on Public Policy in Fiscal Federalism? Tax vs. Expenditure Optimization, September 2008

2386 Ronald McKinnon and Gunther Schnabl, China’s Exchange Rate Impasse and the Weak U.S. Dollar, September 2008

2387 Yan-Leung Cheung, Yin-Wong Cheung and Alan T.K. Wan, A High-Low Model of Daily Stock Price Ranges, September 2008 
2388 Louis Eeckhoudt and Harris Schlesinger, Changes in Risk and the Demand for Saving, September 2008

2389 Carsten Hefeker and Blandine Zimmer, Uncertainty and Fiscal Policy in an Asymmetric Monetary Union, September 2008

2390 Jay Pil Choi and Byung-Cheol Kim, Net Neutrality and Investment Incentives, September 2008

2391 Marcel Gérard, Financing Bologna, the Internationally Mobile Students in European Higher Education, September 2008

2392 Annette Alstadsæter and Knut Reidar Wangen, Corporations’ Choice of Tax Regime when Transition Costs are Small and Income Shifting Potential is Large, September 2008

2393 António Afonso and Christophe Rault, 3-Step Analysis of Public Finances Sustainability: the Case of the European Union, September 2008

2394 Betsey Stevenson and Justin Wolfers, Economic Growth and Subjective Well-Being: Reassessing the Easterlin Paradox, September 2008

2395 Bernhard Eckwert and Itzhak Zilcha, Private Investment in Higher Education: Comparing Alternative Funding Schemes, September 2008

2396 Øystein Foros, Hans Jarle Kind and Jan Yngve Sand, Slotting Allowances and Manufacturers’ Retail Sales Effort, September 2008

2397 Mohammad Reza Farzanegan, Illegal Trade in the Iranian Economy: Evidence from a Structural Model, September 2008

2398 Olivier Bos, Charity Auctions for the Happy Few, September 2008

2399 Robert S. Chirinko and Debdulal Mallick, The Marginal Product of Capital: A Persistent International Puzzle, September 2008

2400 Ben D’Exelle and Arno Riedl, Elite Capture, Political Voice and Exclusion from Aid: An Experimental Study, September 2008

2401 Torben M. Andersen and Joydeep Bhattacharya, On Myopia as Rationale for Social Security, September 2008

2402 Fabienne Llense, French CEO Compensations: What is the Cost of a Mandatory Upper Limit?, September 2008

2403 Valentina Bosetti, Carlo Carraro, Alessandra Sgobbi and Massimo Tavoni, Delayed Action and Uncertain Targets. How Much Will Climate Policy Cost?, September 2008

2404 Robert G. Chambers, Rolf Färe, Shawna Grosskopf and Michael Vardanyan, Generalized Quadratic Revenue Functions, September 2008 
2405 Leonidas Enrique de la Rosa, Overconfidence in a Career-Concerns Setting, September 2008

2406 Marcus Drometer and Johannes Rincke, The Design of Political Institutions: Electoral Competition and the Choice of Ballot Access Restrictions in the United States, September 2008

2407 Markku Lanne and Helmut Lütkepohl, Stock Prices and Economic Fluctuations: A Markov Switching Structural Vector Autoregressive Analysis, September 2008

2408 Thomas L. Brewer, International Energy Technology Transfers for Climate Change Mitigations, September 2008

2409 Alexander Kemnitz, Native Welfare Losses from High Skilled Immigration, September 2008

2410 Xavier Vives, Strategic Supply Function Competition with Private Information, September 2008

2411 Fabio Padovano and Roberto Ricciuti, The Political Competition-Economic Performance Puzzle: Evidence from the OECD Countries and the Italian Regions, September 2008

2412 Joan Costa-Font and Mireia Jofre-Bonet, Body Image and Food Disorders: Evidence from a Sample of European Women, September 2008

2413 Thorsten Upmann, Labour Unions - To Unite or to Separate?, October 2008

2414 Sascha O. Becker and Ludger Woessmann, Luther and the Girls: Religious Denomination and the Female Education Gap in $19^{\text {th }}$ Century Prussia, October 2008

2415 Florian Englmaier and Stephen Leider, Contractual and Organizational Structure with Reciprocal Agents, October 2008

2416 Vittorio Daniele and Ugo Marani, Organized Crime and Foreign Direct Investment: The Italian Case, October 2008

2417 Valentina Bosetti, Carlo Carraro, Alessandra Sgobbi and Massimo Tavoni, Modelling Economic Impacts of Alternative International Climate Policy Architectures. A Quantitative and Comparative Assessment of Architectures for Agreement, October 2008

2418 Paul De Grauwe, Animal Spirits and Monetary Policy, October 2008 